\title{
UNCOVERING THE RELATIONS AMONG RELIGIOSITY, EMPATHIC CONCERN, AND HELPING
}

\author{
By Ryan B. Glaman
}

Certain lines of research support the existence of positive overall relations among religiosity, empathy, and helping, whereas others observe no such relations. These discrepancies may result from inconsistent theoretical definitions, variable operationalizations, and experimental situations. The present study attempted to resolve these inconsistencies to clarify the nature of these relations. One hundred and four university student participants read an ostensible news article describing a fellow student in need of aid. Participants in a realistic helping condition were asked whether they would volunteer to help, whereas participants in a hypothetical helping condition indicated whether they would help if given the opportunity. Intrinsic religious motivation, second naiveté orientation, and religious fundamentalism were all positively correlated with state empathic concern, whereas extrinsic-personal motivation, quest motivation, orthodoxy orientation, and religious fundamentalism were associated with various facets of trait empathy. Regarding helping behaviors, a significant main effect of situation realism indicated that individuals in the hypothetical group were more likely to help than were those in the realistic group. An additional significant main effect of second naiveté religious orientation suggested that those higher in second naiveté were more likely to help than those lower in it. Three significant interactions were found: a) higher intrinsic religious motivation and trait perspective taking predicted increased realistic helping but decreased hypothetical helping, and b) the external critique religious orientation predicted decreased real helping but increased hypothetical helping. Implications of the findings and limitations of the study are discussed. 


\section{UNCOVERING THE RELATIONS AMONG RELIGIOSITY, EMPATHIC CONCERN, AND HELPING}

by

Ryan B. Glaman

A Thesis Submitted

In Partial Fulfillment of the Requirements

For the Degree of

Master of Science-Psychology

Cognitive and Affective Science

at

The University of Wisconsin Oshkosh

Oshkosh WI 54901-8621

May 2013

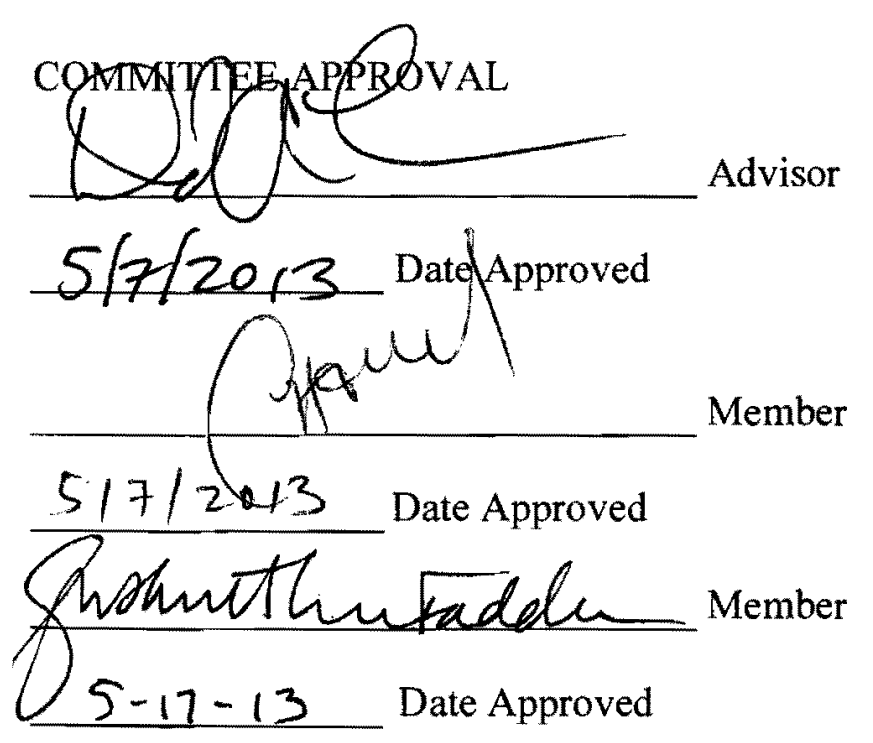

AND VICE CHANCELLOR

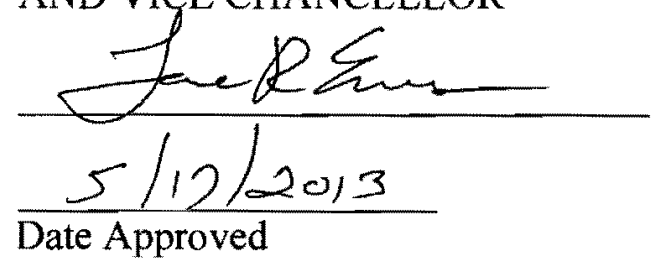

FORMAT APPROVAL

Marai Homan

$\frac{4 / 19 / 13}{\text { Date Approved }}$ 
To God, my family, friends, and everybody else who has helped me along the way. You all know who you are. 


\section{ACKNOWLEDGEMENTS}

I would like to thank and acknowledge my thesis chair Dr. David Lishner, whose constantly-sought advice and expertise was instrumental to this project. I would also like to thank my committee members Dr. Chong Chow and Dr. Susan McFadden for their statistical and theoretical guidance. Thank you to Amanda Fahrner for all her hard work and dedication during data collection. Lastly, I would like to express my appreciation and gratitude toward the entire faculty and staff of the UW-Oshkosh Psychology Department for all their help and input throughout my graduate education. 
TABLE OF CONTENTS

Page

LIST OF TABLES ……………….................................................... vii

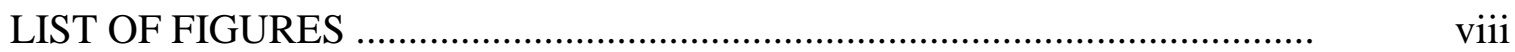

UNCOVERING THE RELATIONS AMONG RELIGIOSITY, EMPATHIC CONCERN, AND HELPING ................................................

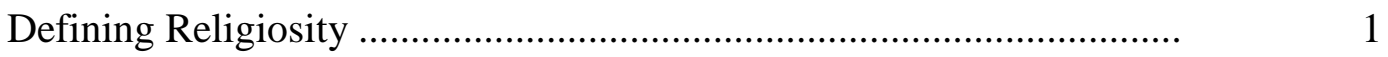

Empathic Concern ...........................................................................

Research on the Interrelations Among Religiosity, Helping,

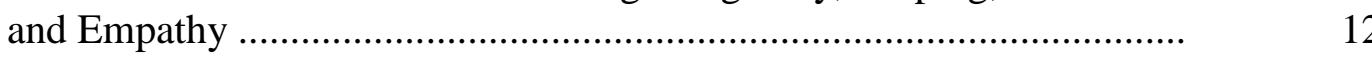

Theoretical and Methodological Inconsistencies Between

Associative and Non-Associative Research ........................................... 16

Goals and Hypotheses of the Present Study ............................................ 18

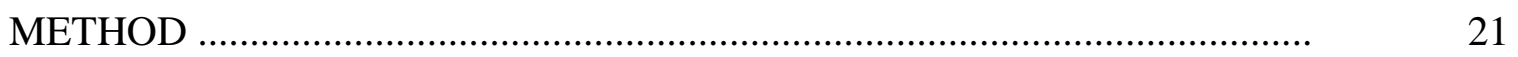

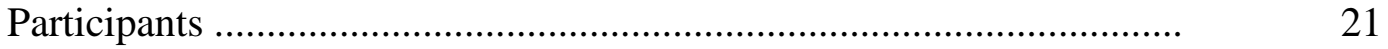

Procedure ................................................................................. 21

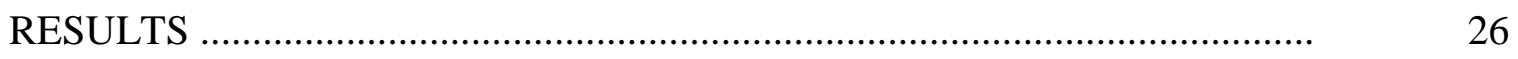

Preliminary Analyses ..................................................................... 26

Relations Between Religiosity and State Empathic Concern .................. 27

Relations Between Religiosity and Trait Empathy ................................. 28

Predictors' Relations With Real and Hypothetical Helping .................... $\quad 30$

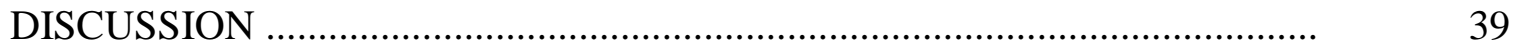

Relation of Current Findings to Previous Research ................................

Limitations and Future Directions ........................................................ 44

Conclusions and Implications ............................................................. 


\section{TABLE OF CONTENTS (Continued)}

\section{APPENDIXES}

Appendix A: Student Newspaper Pilot Articles Study:

Informed Consent......................................................................... 47

Appendix B: Student Newspaper Pilot Articles Study: Introduction ..... 49

Appendix C: Student Newspaper Pilot Article Instructions .................. $\quad 51$

Appendix D: News from the Personal Side: Article .............................. 53

Appendix E: News from the Personal Side: Reactions Questionnaire ... 55

Appendix F: Letter from Dr. Lishner ............................................ 57

Appendix G: Assistance Form ...................................................... 59

Appendix H: News from the Personal Side: Helping Opinions

Questionnaire

61

Appendix I: Evaluation Form ........................................................... 64

Appendix J: Personal Perspective Questionnaires Introduction ............. 68

Appendix K: General Demographics Survey ................................... $\quad 70$

Appendix L: Religious Demographics Survey ....................................

Appendix M: Intrinsic/Extrinsic - Revised Scale ............................. $\quad 76$

Appendix N: Quest Scale ........................................................... 78

Appendix O: Post-Critical Belief Scale ........................................... $\quad 80$

Appendix P: Revised Religious Fundamentalism Scale ....................... 83

Appendix Q: Interpersonal Reactivity Index ..................................... 86

Appendix R: Debriefing Script ..................................................... 89

Appendix S: Student Newspaper Pilot Articles Study: Debriefing

Information 


\section{LIST OF TABLES}

Table 1. Correlations Among Helping, Empathic Concern,

Page

Religiosity Variables, and Trait Empathy Variables for the

Whole Sample

Table 2. Predicting Yes/No Helping from Helping Realism and PCBS Second Naiveté

Table 3. Predicting Yes/No Helping from Helping Realism,

Intrinsic Religious Motivation, and Their Interaction ...............

Table 4. Predicting Yes/No Helping from Helping Realism,

PCBS External Critique, and Their Interaction .........................

Table 5. Predicting Yes/No Helping from Helping Realism, IRI Perspective Taking, and Their Interaction. 


\section{LIST OF FIGURES}

Figure 1. The Theoretical Structure of the Post-Critical Belief Scale

Page

(PCBS, Fontaine et al., 2003) .................................................

Figure 2. The Theoretical Structure of Batson's (2011) Empathy-

Altruism Hypothesis ...............................................................

Figure 3. Line Graph Illustrating the Interaction Between Helping

Realism and Intrinsic Religious Motivation

Figure 4. Line Graph Illustrating the Interaction Between Helping Realism and PCBS External Critique Religious Orientation ....

Figure 5. Line Graph Illustrating the Interaction Between Helping Realism and IRI Perspective Taking 


\section{Uncovering the Relations Among Religiosity, Empathic Concern, and Helping}

Research on religiosity has identified many links between religion and prosociality. One particular branch of research seeks to understand the complex relations among religiosity, empathy (Duriez, 2004), and helping behaviors (Batson, Floyd, Meyer, \& Winner, 1999). However, previous findings have been contradictory, largely due to inconsistent variable operationalizations, theoretical definitions, and situational factors. The present study sought to further explore these relations, utilize more cohesive definitions from both religiosity and empathic concern research, examine one of the glaring methodological inconsistencies of prior research (employing real versus hypothetical experimental helping situations), and subsequently resolve some of the conflicting results observed by other researchers.

\section{Defining Religiosity}

Religiosity, as a construct, is difficult to define in any single clear, concise manner. Definitions have traditionally contained such elements as a search for what is generically referred to as "the sacred," adherence to a particular theological perspective, and ritualized worship practices (Zinnbauer \& Pargament, 2005). Defining religiosity is further complicated by the similar, though not necessarily competing term, spirituality. Although researchers have often defined religiosity based on the practices and behaviors that accompany religion (Bellah, 1970, as cited in Zinnbauer \& Pargament, 2005) and 
defined spirituality based on the actual beliefs toward "the sacred" one possesses (Tart, 1975, as cited in Zinnbauer \& Pargament, 2005), Zinnbauer and Pargament suggest that religiosity and spirituality should each be defined in terms of being some search for significance, which may also be referred to as the sacred.

Zinnbauer and Pargament's (2005) conceptualizations of religiosity and spirituality require an understanding of a few key concepts related to the search for significance. Significance, they suggest, refers to a specific set of valued, meaningful, or ultimate concerns. As humans are goal-directed beings, they often attempt to search for significance in their lives. Once they obtain that which is significant to them, whatever it may be (e.g. self-esteem, social justice, closeness with God, etc.), they attempt to conserve or maintain that significance in their lives. Occasionally, pressures from within individuals or their worlds shift their worldview and require that they transform their understanding of their significance. This transformation then prompts a search for the newly-understood significance, and the process of searching, conservation, and transformation begins again. The final concept one should understand is that of the sacred, which refers to concepts of God, higher powers, or other sanctified aspects of life. Sacred objects and ideas are sources of significance for religious and spiritual people (Zinnbauer \& Pargament, 2005).

With this model of search, conservation, and transformation of significant and sacred concepts in mind, Zinnbauer and Pargament (2005) formulated two sets of definitions of religiosity and spirituality that differ based on the context of the search and 
by the means/ends placement of the sacred. For the first set, in which spirituality is viewed as the broader construct, Zinnbauer defines spirituality as a personal or group search for the sacred and religiosity as a personal or group search that unfolds within a traditional context. Spirituality is a more general search for the sacred, whereas religion serves as a means to engage in that search by adopting a traditional religious perspective (Zinnbauer \& Pargament, 2005). Contrarily, Pargament proposes that religiosity is the broader construct, being defined as a search for significance in ways related to the sacred, whereas spirituality is purely a search for the sacred. In this case, religiosity is a search for the more broadly constructed significance, of which the sacred is one component, whereas spirituality is narrower and involves only the search for the sacred. Although it is arguable as to whether religiosity or spirituality is the broader construct, the present paper will not wrestle with this theoretical debate. Instead, Zinnbauer and Pargament's (2005) theoretical framework of search, conservation, and transformation of significant and sacred concepts was adopted for this paper because it is broad and capable of accommodating many types of religious and spiritual beliefs, practices, and perspectives. More specifically, within the context of the present paper, religiosity is viewed primarily through three theoretical conceptualizations, two of which were employed in previous empathy/religion research.

\section{Intrinsic, extrinsic, and quest motivations.}

Originally established by Gordon Allport (Allport \& Ross, 1967), the intrinsic/extrinsic motivation theory is designed to categorize individuals' types of 
religious motivations. Since its creation, the intrinsic/extrinsic motivational theory has become a prominent means of operationalizing and measuring religiosity in religion research (Kirkpatrick and Hood, 1990). Furthermore, by measuring individuals' various motivations, the present study may shed some light on what drives individuals to engage in helping behaviors.

People who are extrinsically motivated view their religion as a means to achieve other ends, religious or non-religious (Kahoe, 1985). Individuals high in this motivation use their religion in order to obtain things such as feelings of safety, social status, wealth, and so forth. Those who are intrinsically motivated view their religion not as a means, but as an end unto itself. Their religion becomes their primary motive in life, not merely a tool to achieve other ends. Often, the analogy is made that extrinsically motivated people use their religion, whereas intrinsically motivated people live their religion. These two motivations are typically viewed not as bipolar ends of a single continuum and therefore mutually exclusive; rather, they are usually viewed as two separate motivations that an individual may possess (Kahoe, 1985). Note that this view results from a more datadriven perspective; based on Allport's original theoretical conceptualizations of intrinsic an extrinsic motivation, the case could be made that the two motivations actually lie on one continuum (Kirkpatrick \& Hood, 1990).

Kirkpatrick (1988, as cited in Gorsuch \& McPherson, 1989) made some revisions to the original intrinsic/extrinsic theory that will be incorporated into the present study. Specifically, he subdivided extrinsic motivation into two more specific motivations: 
personally extrinsic and socially extrinsic. Personal motivations include such elements as feelings of security, a sense of happiness, and so forth, whereas socially extrinsic motivations are more relationship-oriented, with the religion being used to help individuals make friends or maintain social bonds with others.

Some attention has been drawn to the overall usefulness of the intrinsic/extrinsic theory. Kirkpatrick and Hood (1990) have criticized Allport's theory, stating that imprecise definitions, such as using the terms "motivation" and "orientation" interchangeably, lack of clarity of the relation between intrinsic and extrinsic motivation, and the overall value-laden nature of the theory ("good" intrinsic motivation versus "bad" extrinsic motivation) prevent it from being wholly useful. Although Gorsuch and McPherson's (1989) Intrinsic/Extrinsic-Revised Scale (I/E-R) does psychometrically account for the confusing relation between intrinsic and extrinsic motivations to some extent, it does not account for some of the theory's overall theoretical shortcomings. Pargament (1992) attempted to alleviate the theory's value-laden nature by suggesting that religion should be thought of as "means and ends" as opposed to "means or ends." If religion is a search for the sacred, then all searches must have pathways (means) and destinations (ends). He suggests that the intrinsic motivation construct should not simply present religion as an end, nor should extrinsic motivation be viewed simply as a means. Both motivations have means and ends and neither is inherently "good" nor "bad." For example, intrinsically, living one's religion as a way of life may serve as a means to be with God; similarly, an extrinsic means of using one's religion as a crutch during hard 
times may be used to achieve feelings of safety and comfort. Such revisions and other insights into the theory could help ease some of its theoretical shortcomings and aid in its application to the present study.

Quest, a third religious motivation theorized by Batson (Batson \& Schoenrade, 1991a, 1991b), focuses not on the means or the ends of religion; instead, it emphasizes the active search for what is sacred. Individuals high in quest motivation view that search as their master motivation. People high in quest motivation tend to possess three qualities: a readiness to face existential questions without reducing their complexity, perception of religious doubts as positive, and an openness to change (Batson \& Schoenrade, 1991b).

\section{Wulff's religious orientation model.}

In addition to the intrinsic/extrinsic/quest motivational theories, the present study defined religiosity in terms of Wulff's (1991) religious orientation model. Originally created by Wulff as a method of categorizing theoretical viewpoints in the psychology of religion, the model has since been adopted as a means of defining various religious orientations (Duriez, Fontaine \& Hutsebaut, 2000). As described below, religious orientation is qualitatively different than religious motivation, and Wulff's framework was used because it is thorough and encompasses a variety of religious, atheistic, and spiritual orientations.

Different religious orientations or approaches to religion can be established based on two overarching dimensions that can be arranged in a two-dimensional space 
(Fontaine, Duriez, Luyten, \& Hutsebaut, 2003; see Figure 1). The first dimension, Inclusion versus Exclusion of Transcendence, indicates whether or not and to what extent the individual is a believer in a higher power. The second dimension, Literal versus Symbolic Processing, describes whether the individual processes religious information literally (e.g., the Bible is the literal word of God) or symbolically (e.g., the Bible is largely made up of metaphors designed to instill a more general lesson) (Fontaine et al., 2003).

Individuals' positions on these two axes will place them in one of four religious orientations (Fontaine et al., 2003). Believers who process religious information literally fit into the literal affirmation category and are labeled as "Orthodoxy." Such people can often be described as being religious fundamentalists. Contrarily, literally-processing nonbelievers fall into the "External Critique" category and examples of such individuals include atheists and the indiscriminately anti-religious. Symbolically-processing believers fit into the "Second Naiveté" category. Based largely on the work of Paul Ricoeur, people in this category are theorized to have a higher-level understanding of their faith than those in the more primitive first naiveté, and possess a restorative interpretation of their faith (Bingaman, 2003). Through critical examination and reflection on their faith, individuals' religious perspectives transform and they gain a deeper understanding and more mature interpretation of their faith. Finally, the relatively nonreligious who still process religious information symbolically fit into the "Relativism" category. Relativists 
claim to understand the morals and lessons religion often preaches while simultaneously choosing to not adhere to a belief in a higher power.



Figure 1. The theoretical structure of the Post-Critical Belief Scale (PCBS, Fontaine et al., 2003). 


\section{Religious fundamentalism.}

The final conceptualization of religiosity used in the present paper, religious fundamentalism, is the belief that there is one set of religious teachings that contains the fundamental, essential, and inerrant truth about humanity and deity (Altemeyer \& Hunsberger, 2004). Although Wulff's Orthodoxy orientation (Fontaine et al., 2003) is a similar construct to religious fundamentalism, the present paper employs a dedicated measure of fundamentalism for the purposes of redundancy and having a non-religionspecific measure of fundamentalism. Although the measure that assesses Wulff's orientations, the Post-Critical Belief Scale (PCBS; Duriez, Soenens, \& Hutsebaut, 2004), is framed from a primarily Christian perspective, the religious fundamentalism scale is not. The presence of religious fundamentalism has been demonstrated across many faiths including Hindus, Jews, Muslims, and Christians (Altemeyer \& Hunsberger, 2004).

\section{Empathic Concern}

In addition to understanding the religious theories and models the current study was predicated on, one must also have a rudimentary knowledge of empathic concern and the empathy-altruism hypothesis. Batson (2011) defines empathic concern as an otheroriented emotion elicited by and congruent with the perceived welfare of someone in need. Two antecedents lead to feelings of empathic concern for another: perceiving the other as in need and genuinely valuing his or her welfare. Much of the research to be 
discussed investigates religiosity's relation to "empathy," a term that is theoretically confusing and has several possible definitions (Batson, 2011) including:

- Imagining how another is thinking and feeling.

- Imagining how one would think and feel in another's situation.

- Knowing another's internal state, thoughts, and feelings.

- Projecting oneself onto another's situation.

- Feeling as another person feels.

- Feeling empathic concern.

- Feeling distress at witnessing another's suffering.

- Adopting the posture and matching the neural response of another.

Many studies investigate "empathy's" relation to religiosity; however, for the sake of theoretical precision and cohesion, the present study will be specifically investigating empathic concern's relation to religiosity.

Empathic concern, the emotional response to perceiving another as in need while intrinsically valuing his or her welfare, is only the first component of Batson's (2011) empathy-altruism hypothesis (see Figure 2). When empathic concern for another is generated, it produces an altruistic motivation to help that other (Batson, 2011). An altruistic motivation, or simply altruism, is a motivational state with the ultimate goal of improving the other's welfare. Note that this is opposed to an egoistic motivation in which the ultimate goal is to increase one's own welfare. Altruism, in conjunction with a 
cost-benefit analysis of possible helping (or not) behaviors, leads individuals to help the person in need, have or allow another person help, or not act.

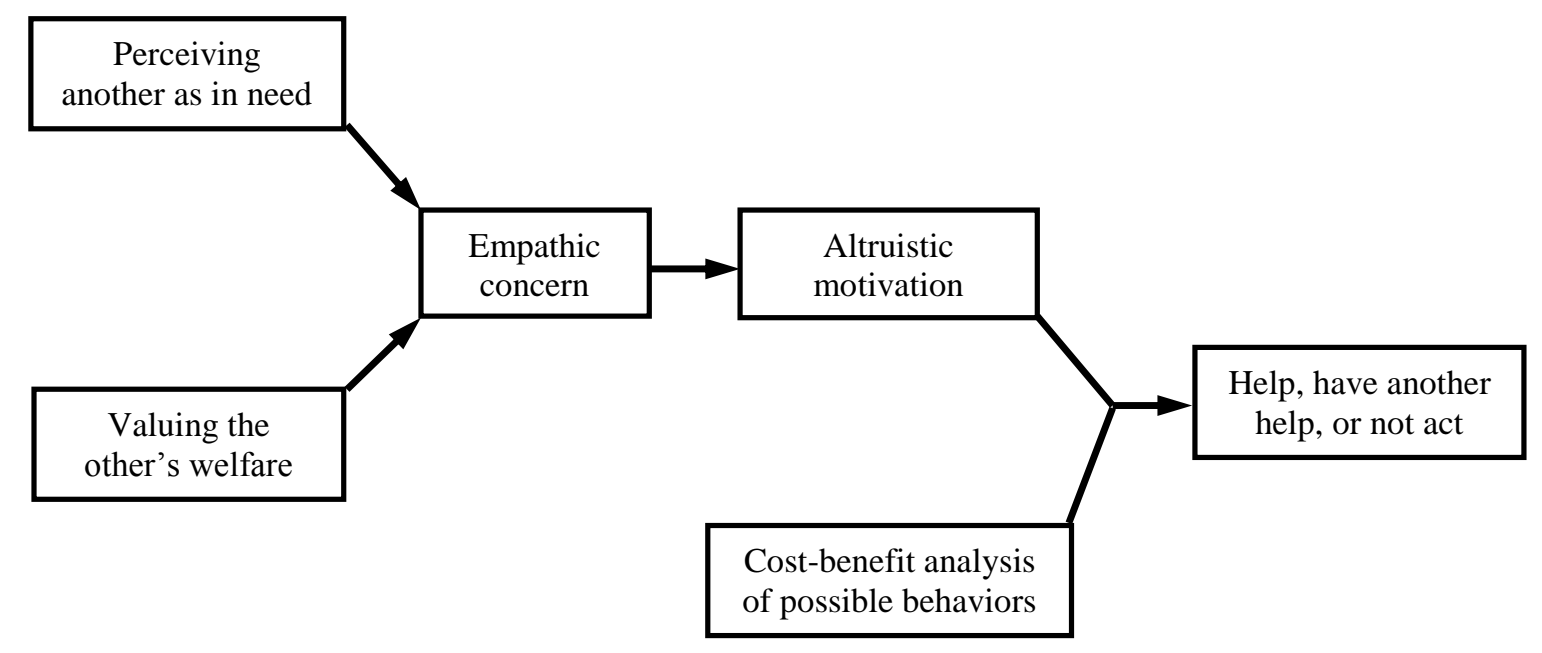

Figure 2. The theoretical structure of Batson's (2011) empathy-altruism hypothesis.

It is important to note that altruism is a motivation, not a specific behavior per se.

Like empathy, altruism has multiple definitions including:

- A helping behavior.

- Acting morally.

- Helping to gain internal (but not external) rewards.

- Benefitting others to decrease aversive arousal caused by witnessing others' suffering.

- Increasing the welfare of another as an end in itself. 
To maintain theoretical cohesiveness, Batson's (2011) definition of altruism and the empathy-altruism hypothesis as a whole will be adopted for the present study. The process of feeling empathic concern for a target and subsequently altruistically helping him or her in some way is the process that will be examined in its relation to religious motivation and orientation. Note that some of the research to be discussed will focus on altruism rather than empathic concern. Despite altruism and empathic concern being separate constructs, their relation preserves the relevance to the current review of the research described below.

\section{Research on the Interrelations Among Religiosity, Helping, and Empathy}

Nearly all world religions promote altruism and prosocial behaviors as being moral. In the Christian Bible, for example, numerous passages can be found urging readers to love thy neighbor as thyself (Mark 12:31), donate to the poor (Matthew 19:21), and put the needs of others above the needs of oneself (Acts 20:35). Allport himself (1966, as cited in Batson, Oleson, Weeks, et al., 1989) purported that an intrinsic religious motivation would produce genuine care for others, thus resulting in an altruistic motivation to help. Although some lines of research support the existence of a positive relation between religiosity and prosociality, several studies also refute the existence of said relation. Each line of research will be reviewed in turn, and possible reasons for discrepant results will be discussed. 


\section{Positive overall association between religiosity and empathy.}

Maclean, Walker, and Matsuba's (2004) research reinforced Allport's original hypothesis, showing that intrinsic religious motivation is positively associated with altruism. Furthermore, this relation is not affected by impression management, though it may be an artifact of self-deception, which is the unconscious tendency to provide honest but positively-biased self-reports. Similarly, across a series of studies, Saroglou and colleagues (2005) observed that the importance of both religiosity and spirituality in participants' lives were positively related to altruism, empathy, and perspective taking. Interestingly, in regard to the importance of religiosity variable, this tendency toward altruism and empathy was directed only toward in-group members (familiar people), not out-group members (unfamiliar people). Pichon and Saroglou (2009) observed that priming for religious salience led participants to be more willing to provide aid to people in need. Like Saroglou and colleagues' (2005) results, this tendency to help was limited only to more socially proximal targets (homeless persons) rather than more distant outgroup ones (illegal immigrants). The social proximity trend notwithstanding, the above studies reported that higher levels of religiosity (intrinsic or otherwise) corresponded to higher levels of empathy and helping.

Pichon and Saroglou (2009) employed the PCBS, which measures Wulff's (1991) religious orientations, observing that religious orthodoxy was associated with increased discrimination and racism, whereas the more symbolic religious orientations of second naiveté and relativism produced more helping responses. Duriez (2004) also found that 
the PCBS's Literal versus Symbolic dimension was significantly correlated with perspective taking and empathy. The more participants symbolically processed religious information, the more empathic they were overall. The Inclusion versus Exclusion of Transcendence subscale was not significantly correlated with empathy. Perhaps the relation between religiosity and empathy is not the result of whether one is religious or not, but stems from how one interprets religious texts, symbols, and so forth.

\section{No overall association between religiosity and empathic concern.}

Batson's line of religiosity and empathic concern research has produced results contrary to Allport's original hypotheses (1966, as cited in Batson, Oleson, Weeks, et al., 1989) and the results described above. Batson, Oleson, Weeks, and colleagues (1989) observed that intrinsic, end-state religiosity is not positively related to altruism, but rather to more egoistic goals of esteem-enhancing rewards. However, they also conceded that such results were not conclusive and more research on the topic was necessary. A collection of studies identified a series of interrelations among intrinsic, extrinsic, and quest religiosity and helping behaviors (Batson, Denton, \& Vollmecke, 2008; Batson, Eidelman, Higley, \& Russell, 2001; Batson et al., 1999). Similar to the previously discussed line of research on helping in- versus out-group members, these studies suggest that those who score highly on Allport's intrinsic motivation scale helped morality nonviolators more frequently than morality violators: when given the option, the highly intrinsically motivated helped heterosexuals win money to finance a road trip more than they helped homosexuals achieve the same goal. Yet again, regardless of the in- versus 
out-group variable, there was no overall association between high levels of intrinsic religious motivation and rates of helping: those low in intrinsic motivation helped just as frequently as did those high in intrinsic motivation. Similarly, those high in quest motivation were less willing to help morality violators such as religious fundamentalists than morality non-violators (non-fundamentalists) (Batson et al. 2008). Again, there was little average difference between those high and low in quest motivation.

Batson and colleagues (2008) propose that, contrary to Allport's original hypotheses (1966, as cited in Batson, Oleson, Weeks, et al., 1989), intrinsic religious motivation is not associated with higher levels of altruism and helping. Rather, intrinsic motivation is negatively associated with helping those who possess morality-violating beliefs (being a homosexual) and engage in morality-violating behaviors (attending a gay pride rally), whereas those high in quest motivation are willing to help those with morality-violating beliefs (being a religious fundamentalist), but not violating behaviors (attending a fundamentalist rally). Based on this observation, Batson et al. (2008) purport that quest religious motivation is more associated with universal compassion and helping than is intrinsic motivation.

Regardless of which motivation is a marginally better source of empathic concern, Batson's findings directly oppose those observed by the research discussed in the previous section: little overall difference in empathic concern and helping rates exists between those high and low in the three religious motivations. However, this opposition must be qualified by several theoretical and methodological differences and 
inconsistencies between the two research categories. Next, attention will be directed toward identifying these discrepancies and discussing how they will be reconciled to produce more consistent results for the present experiment. For clarification, from this point forward, the group of studies that has identified positive associations between religiosity and empathy/helping will be referred to as the "associative" research branch, whereas Batson's line of research that observed no such relations will be referred to as the "non-associative" research branch.

\section{Theoretical and Methodological Inconsistencies Between Associative and Non-}

\section{Associative Research}

Theoretical issues arise when researchers test constructs that are theoretically imprecise. The associative research on religiosity and empathy/altruism generally defines altruism specifically as helping behaviors (Maclean et al., 2004; Pichon \& Saroglou, 2009; Saroglou et al., 2005; Seth \& Gupta, 1984). In contrast, Batson views altruism as a motivation, not a behavior (Batson, 2011). Furthermore, the associative research employs the construct empathy (Duriez, 2004; Saroglou et al., 2005). As previously discussed, empathy has a vague definition and can be used to define numerous phenomena (Batson, 2011). The present study examines the more specific construct from Batson's empathyaltruism hypothesis: empathic concern.

In addition to the differentiating empathy from empathic concern, researchers also distinguish trait empathy from state empathy. Trait empathy reflects a general tendency 
to express empathic states across situations. For example, via the Interpersonal Reactivity Index (IRI; Davis, 1983), empathy is measured using four subscales framed as personality traits: empathic concern (e.g., "I often have tender, concerned feelings for people less fortunate than me"), perspective taking (e.g., "I sometimes try to understand my friends better by imagining how things look from their perspective"), personal distress (e.g., "Being in a tense emotional situation scares me"), and fantasy (e.g., "I really get involved with the feelings of the characters in a novel"). Associative research tends to use trait empathy as the primary empathy measure (Duriez, 2004). State empathy, on the other hand, measures situational in-the-moment empathic reactions (Batson, Batson, Griffitt, et al., 1989). Measures of trait empathy have the potential to be artifacts of social desirability or self-deception (Saroglou et al., 2005). However, more covert measures of state empathy such as the one employed in the current study have the capacity to be more accurate measures of participants' actual empathic concern. Because state measures of empathy tend not to be reflective of one's reactions across multiple situations and time, they may be less prone to response biases.

Correspondingly, associative research has typically employed hypothetical helping responses as the dependent measures (Pichon \& Saroglou, 2009; Saroglou et al., 2005; Seth \& Gupta, 1984), asking participants if they were in a hypothetical situation, how would they behave? The non-associative research has employed deception to create more "real" helping situations (Batson et al., 2008; Batson et al., 2001; Batson et al., 1999) in which participants, in a more realistic experimental situation, actually choose 
whether to help a target person or not. Although Batson's series of studies employ a more realistic methodology, he does make the statistical error of employing median splits in his analyses. By dichotomizing intrinsic, extrinsic, and quest motivations into "high" and "low," Batson sacrifices much potentially important variability, which may reduce statistical power to detect meaningful associations among religious motivations, empathic concern, and helping.

Finally, while not a shortcoming per se of previous research, the current study will not focus on the social proximity component of prior research. That is, the present research does not look at participants' responses toward closer (e.g., family members) versus distant (e.g., strangers) targets. Although that variable does provide valuable information regarding the complex nature of the interrelations among religiosity, helping, and empathic concern, the aforementioned theoretical inconsistencies and contradictory findings will serve as the main focus of the present study.

\section{Goals and Hypotheses of the Present Study}

As previously stated, the associative and non-associative lines of research have produced divergent findings. Furthermore, previous studies typically complicate the religiosity-empathic concern relation by focusing on constructs not strictly related to religion and empathic concern such as social proximity (Pichon \& Saroglou, 2009), political preference (Wuthnow \& Lewis, 2008), and so forth. Therefore, the present study had an overarching goal of being an exploratory study investigating the interrelations 
among religiosity, helping, and empathic concern at the most basic, fundamental level, excluding as many external factors as possible.

Prior research has been based on varying operationalizations of empathy, altruism, and religiosity, contributing to the conflicting findings. The current study employed more consistent theoretical definitions including Batson's (2011) definition of empathic concern and elements from the empathy-altruism hypothesis. Religiosity was operationalized primarily using the intrinsic/extrinsic/quest motivational dimensions, Wulff's (1991) religious orientations, and religious fundamentalism. The religious motivation and orientation models have been employed in empathy and religiosity research before, providing some (albeit flawed) background information to draw upon.

Procedurally, studies that have identified consistent relations among religiosity, helping, and empathy have utilized hypothetical helping situations (Pichon \& Saroglou, 2009; Saroglou et al., 2005), whereas those that have failed to observe such relations have employed more realistic helping scenarios (Batson et al., 1999). This methodological divergence may be related to the discrepant findings. Therefore, the present study's experimental manipulation placed half the participants in a situation in which they were asked to literally help a target in need, whereas the other half were placed in a hypothetical helping situation. This manipulation was employed to clarify whether level of realism was an important factor in determining helping rates relative to religiosity. 
The present study's hypotheses were based on the findings of the associative and non-associative branches of research (Batson et al., 1999; Saroglou et al., 2005). In the hypothetical helping condition, it was hypothesized that empathy and helping would be positively associated with demographic religiosity (i.e., self-identifying as "religious" or "nonreligious"), intrinsic religious motivation, and the second naiveté religious orientation. In contrast, in the realistic helping situation, empathic concern and helping were hypothesized to be unrelated to the religiosity variables, save for a potential positive association with quest motivation (Batson et al., 1999). 


\section{Method}

\section{Participants}

One hundred and six participants were drawn from the University of Wisconsin Oshkosh human participant pool; however, two participants were excluded due to suspicion of the deceptive elements of the procedure, reducing the total to 104 participants. Participants were mixed in terms of age $(M=19.52, S D=2.85)$, and sex (43 males, 61 females), and were primarily Caucasian (85.6\%). The study took approximately one hour to complete and participants were compensated with two research credits toward their General Psychology research requirement.

\section{Procedure}

Introduction.

The present study employed the Katie Banks paradigm, a method used in previous empathic concern research (Batson, Batson, Griffitt, et al., 1989). Participants took part in the study on an individual basis. Participants entered the lab and were greeted by the research assistant who provided them with informed consent detailing that the study would involve reading a pilot news article (see Appendix A). After being given the opportunity to read the form, ask any questions they may have, and provide consent, participants read an introduction stating that they would select and read one of eight different news articles for the school newspaper (see Appendix B). Participants then 
selected a number between one and eight, indicating which article they would like to read. The researcher then left the room to retrieve the article chosen by participants. However, participants were only given the illusion of choice. In fact, all participants read the same article. The researcher then returned to the lab with a folder labeled with participants' chosen number. Inside the folder was an instruction sheet and the news article (see Appendixes $\mathrm{C}$ and $\mathrm{D}$ respectively).

\section{Measure of empathic concern.}

The researcher left the room and participants opened the folder, reviewed the instructions, and read the news article, which was about a university student named Katie Banks whose parents and younger sibling recently died in an automobile accident, and who now has to raise her remaining younger siblings by herself in addition to attending the university. Despite these issues, Katie is confident that her situation will improve. Note that, unbeknownst to participants, the article was fictitious. The researcher also provided participants with an emotional reactions questionnaire to complete after they had read the article (see Appendix E). The reactions questionnaire included six items used to create a composite state empathic concern score (Batson, Batson, Griffitt, et al., 1989): sympathetic, compassionate, softhearted, tender, moved, and warm. Participants were left alone to read the article and complete the reactions questionnaire.

\section{Manipulation of helping situation realism and measure of helping.}

Once participants completed the reactions questionnaire, the helping realism manipulation took place. In the "real helping" condition, the researcher returned and gave 
participants a letter ostensibly from Dr. Lishner (see Appendix F) describing Katie's current need and asking the participant if they would be willing to volunteer their time to help Katie prepare letters to charitable organizations and stuff envelopes. Participants then completed the enclosed assistance form (see Appendix G), indicating whether or not and how many hours they would be available to help. The form included a dichotomous yes/no question regarding whether participants were able to help followed by a question regarding how many hours in the coming weeks they could volunteer. Participants in the "hypothetical helping" condition simply received the "Helping Opinions Questionnaire" (see Appendix H), which contained several questions regarding various hypothetical helping activities, each in the same dichotomous yes/no and continuous hours question format. The primary hypothetical helping activity of interest was preparing letters and stuffing envelopes (parallel to the realistic helping condition). Other activities included on the questionnaire were providing automobile transportation, babysitting, and donating money, all of which are activities presumably more costly in terms of time and money to the participant than stuffing envelopes. Participants in both groups then completed an article evaluation form (see Appendix I) containing questions regarding the extent to which participants perceived Katie to be in need.

Again, participants signaled to the researcher that they were finished and the researcher collected the completed helping forms and provided them with a battery of questionnaires as well as an introduction to the battery and its purpose (see Appendix $\mathbf{J}$ ). The first two surveys were measures of participants' general and religious demographics 
(see Appendixes K and L respectively). Following those, participants completed the Intrinsic/Extrinsic - Revised Scale (I/E-R; Gorsuch \& McPherson, 1989; Hill \& Hood, 1999; see Appendix M), a 14-item measure of intrinsic and extrinsic religious motivations. The survey is based on Kirkpatrick's (1988, as cited in Gorsuch \& McPherson, 1989) revisions to Allport's original motivational theory, featuring three subscales: intrinsic, extrinsic-personal, and extrinsic-social religious motivations. Next, participants completed the 12-item Quest Scale (Batson \& Schoenrade, 1991a, 1991b; Hill \& Hood, 1999; see Appendix N), designed to measure level of quest religious motivation.

Participants then filled out the PCBS (Duriez et al., 2004; see Appendix O), an 18-item questionnaire assessing individuals' levels of each of Wulff's (1991) four religious orientations via four distinct subscales: orthodoxy, second naiveté, external critique, and relativism. Next, participants completed the 12-item Revised Religious Fundamentalism Scale (Altemeyer \& Hunsberger, 2004; see Appendix P). This questionnaire used one scale to assess religious fundamentalism, which is defined as the belief that there is one set of religious teachings that contain the basic, inerrant truth about humanity and deity. Finally, participants completed the 28-item IRI (Davis, 1983); see Appendix Q). The IRI assessed levels of trait empathy and contains four subscales: fantasy, empathic concern, perspective taking, and personal distress.

After completing the survey battery, participants were carefully debriefed using a semi-structured script (see Appendix R). They were given a debriefing information form 
(see Appendix S) outlining all elements of deception used in the study and had the opportunity to ask any questions they may have had. Following the debriefing, participants were dismissed from the lab. 


\section{Results}

\section{Preliminary Analyses}

Prior to analysis, index scores were computed for the state empathic concern, religiosity, and trait empathy measures. As previously stated, participants' scores on the state empathic concern scale were computed by averaging the scores of six items on the reactions questionnaire: sympathetic, compassionate, softhearted, tender, moved, and warm (Batson, Batson, Griffitt, et al., 1989; Cronbach's $\alpha=.65$ ). Using the I/E-R, participants' scores on the intrinsic (Cronbach's $\alpha=.82$ ), extrinsic-social (Cronbach's $\alpha=$ .82 ), and extrinsic-personal (Cronbach's $\alpha=.73$ ) subscales were computed by summing items from the corresponding subscales and quest scale scores (Cronbach's $\alpha=.82$ ) were created by averaging the values of participants' Quest Scale responses (Hill \& Hood, 1999). Post-Critical Belief Scale index scores for the four religious orientations of orthodoxy (Cronbach's $\alpha=.70$ ), second naiveté (Cronbach's $\alpha=.54)$, external critique (Cronbach's $\alpha=.80$ ), and relativism (Cronbach's $\alpha=.61$ ) were created by averaging scores on the corresponding items (Duriez et al., 2000) and religious fundamentalism scores (Cronbach's $\alpha=.90$ ) were established by summing the values of all responses on the Revised Religious Fundamentalism Scale (Hunsberger, Alisat, Pancer, \& Pratt, 1996). Finally, index scores for the four IRI subscales of fantasy (Cronbach's $\alpha=.78$ ), empathic concern (Cronbach's $\alpha=.78$ ), perspective taking (Cronbach's $\alpha=.71$ ), and personal distress (Cronbach's $\alpha=.76$ ) were computed by summing the values of the appropriate 
items (De Corte, Buysse, Verhofstadt Roeyers, Ponnet, \& Davis, 2007). For the duration of the analyses, unless otherwise specified, the "helping" variable constitutes participants' responses to the dichotomous yes/no helping item $(0=$ No, $1=$ Yes $)$.

\section{Relations Between Religiosity and State Empathic Concern}

Before investigating the relations among religiosity and empathy variables, a multiple analysis of variance (MANOVA) was conducted to investigate the potential effects of the helping realism manipulation on all the variables. Presumably, because the state empathic concern measure was administered before the manipulation took place and the religiosity and trait empathy variables represent relatively stable constructs, they should have all been unaffected by the manipulation; the MANOVA confirmed this assumption, Wilks' $\Lambda=.89, F(14,76)=.69, n s$, multivariate $\eta^{2}=.11$.

Additionally, several multiple regression analyses were used to test the interaction effects between helping realism and the religiosity and trait empathy variables on state empathic concern. Because not all the variables used the same scale, all predictors were standardized prior to analysis. Interaction terms between the predictors and helping realism were computed by multiplying the standardized predictor values with helping realism condition dummy codes $(0=$ realistic helping condition, $1=$ hypothetical helping condition). Each predictor was tested individually and, for all analyses, helping realism and the predictor variable were entered in step one and their interaction term was entered in step two. A total of thirteen multiple regression analyses were conducted in this 
fashion and none of the interaction terms significantly predicted state empathic concern (all $\beta \leq .37, t(97) \leq 1.88, n s)$. Because the experimental manipulation had no effect on the religiosity and empathy variables, and none of the helping realism/predictor interactions were predictive of state empathic concern, bivariate correlations for the entire sample could be used to examine the relations among these variables.

Bivariate correlations among helping, religiosity, state empathic concern, and trait empathy are presented in Table 1 . The results suggest that intrinsic religious motivation, second naiveté orientation, and religious fundamentalism were all significantly positively related to state empathic concern. While the associative research branch has typically employed trait empathy measures (Duriez, 2004), the present findings regarding intrinsic motivation and the second naiveté orientation represent an extension of previously observed trait empathy associations to a more situational, state context.

\section{Relations Between Religiosity and Trait Empathy.}

Again, correlations among all study variables can be seen in Table 1. Extrinsicpersonal religious motivation and orthodoxy orientation were positively associated with trait empathic concern as measured by the IRI. Additionally, scores on the IRI's Fantasy subscale were positively correlated with quest motivation and negatively correlated with religious fundamentalism. Interestingly, although the correlational findings regarding state empathic concern were representative of the findings of the associative research branch (Duriez, 2004), the findings regarding the actual trait empathy variables were not. 


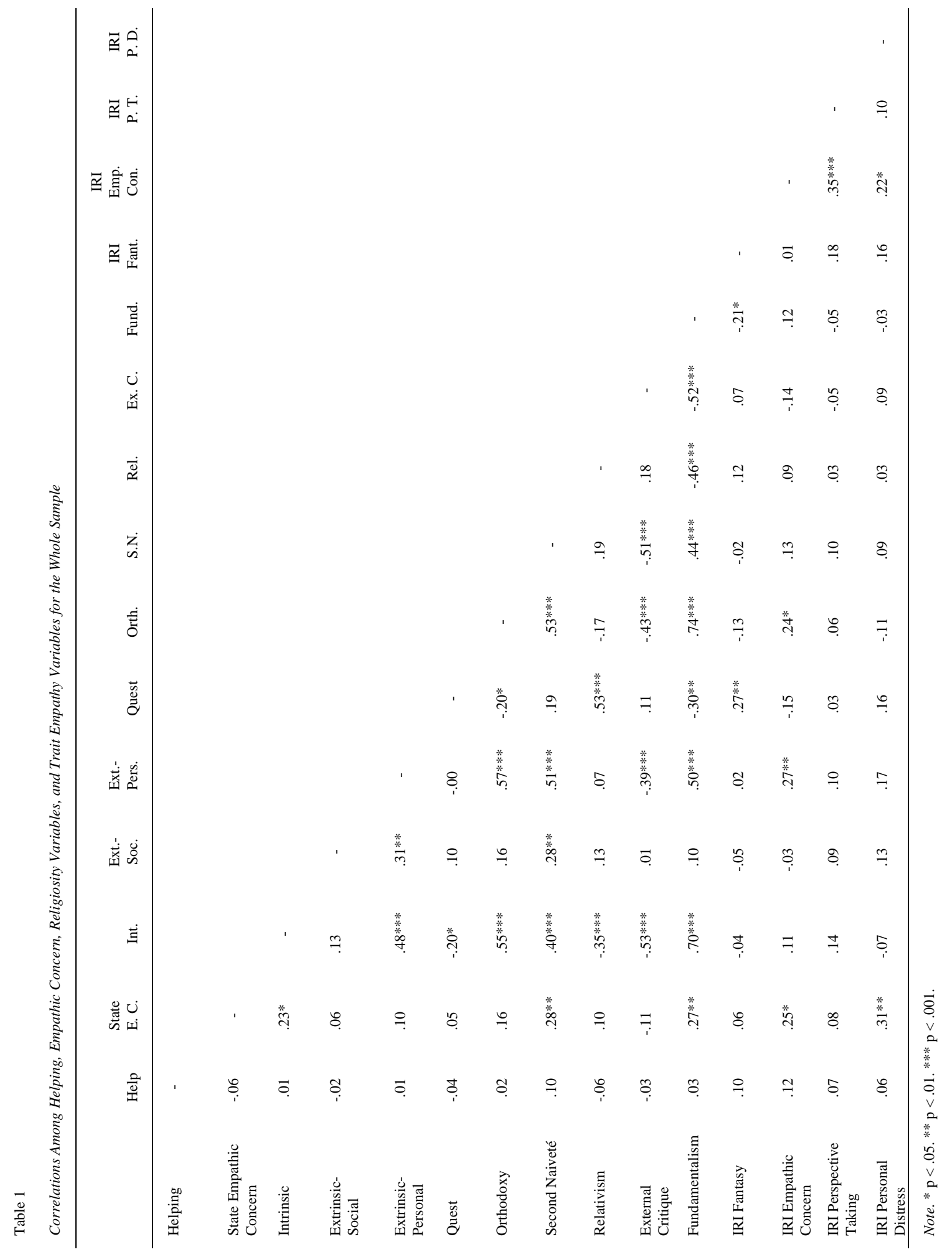




\section{Predictors' Relations With Real and Hypothetical Helping}

State empathic concern was not significantly correlated with helping. Because Batson's (2011) empathy-altruism hypothesis necessitates a positive relation between state empathic concern and helping behaviors and the present results failed to observe such a relation (see Table 1), the current study could not examine the presence of altruistic motivations among participants. Subsequently, the following logistic regression analyses could be used only to investigate relations involving the helping realism manipulation, religiosity and trait empathy predictors, and helping behaviors.

\section{Helping realism manipulation main effect.}

Logistic regression was used to test the effect of the experimental manipulation of helping realism on yes/no helping responses. A test of the full model with one predictor compared to a constant-only model was statistically significant, $\chi^{2}(1)=27.50, p<.001$, Nagelkerke's $R^{2}=.31$. Helping realism was a significant predictor of helping responses $\left(\beta=-2.24\right.$, Wald $\left.\chi^{2}(1)=23.44, p<.001\right)$. The Odds ratio for group membership indicated that helping rates were about .11 times lower in the realistic helping condition compared to the hypothetical condition. To help illustrate this point, overall helping percentages for both groups were computed: $81.13 \%$ of participants in the hypothetical condition said they would help if given the opportunity while only $31.37 \%$ of participants in the realistic condition actually volunteered to help.

Although no significance tests were conducted, it is worth noting that the helping proportions for the additional hypothetical helping activities were all higher than helping 
rates in the realistic condition. In the hypothetical condition, $52.83 \%$ of participants indicated they would volunteer to babysit Katie's younger siblings, $56.60 \%$ said they would provide automobile transportation, and $47.17 \%$ stated they would donate money. Note that the hypothetical helping proportions for these presumably more costly activities were all greater than the proportion of students who actually volunteered to help in the lower-cost realistic condition.

\section{Religiosity, trait empathy, and interaction effects.}

Several sequential logistic regression analyses were conducted to investigate the effects of helping realism, religiosity and trait empathy, and their interactions on helping. As with the previous multiple regression analyses, because not all the variables used the same scale, the standardized predictors and interaction terms described above were employed for these analyses. Each predictor was tested individually and, for all analyses, helping realism and the predictor variable were entered in step one and their interaction term was entered in step two. Thirteen logistic regression analyses were conducted in this way and, while they all produced significant overall models due to the main effect of group membership (all $\chi^{2}(3) \geq 26.14, p<.001$; all $\beta \geq-2.21$, Wald $\chi^{2}(1) \geq-2.21, \mathrm{p}<$ .001 ), only one significant religious orientation main effect and three significant interactions were observed; the majority of religiosity and trait empathy predictors did not uniquely predict helping (all $\beta \leq .36$, Wald $\chi^{2}(1) \leq .2 .49, n s$ ), nor did most of the interaction terms (all $\beta \leq-.65$, Wald $\left.\chi^{2}(1) \leq 1.64, n s\right)$. The significant predictor and interaction effects will be discussed below. 
There was a significant main effect of the Post-Critical Belief Scale (PCBS) second naiveté orientation on helping, $\chi^{2}(2)=33.23 p<.05$, Nagelkerke's $R^{2}=.37$. Beta weights for second naiveté and helping realism are displayed in Table 2. These results suggest that those higher in the second naiveté orientation are 1.61 times more likely to offer help, regardless of whether the helping situation is real or hypothetical.

Table 2

Predicting Yes/No Helping from Helping Realism and PCBS Second Naiveté

\begin{tabular}{lccccc}
\hline & $B$ & $S E$ & Wald & $d f$ & Odds Ratio \\
\hline $\begin{array}{l}\text { Helping } \\
\text { Realism }\end{array}$ & $-2.58^{* * *}$ & .52 & 25.04 & 1 & .08 \\
$\begin{array}{l}\text { Second } \\
\text { Naiveté }\end{array}$ & $.48^{*}$ & .24 & 3.92 & 1 & 1.61 \\
& & & & & \\
Constant & $1.71^{* * *}$ & .39 & 18.83 & 1 & 5.54 \\
\hline Note. ${ }^{*} \mathrm{p}<.05 . * * \mathrm{p}<.01 . * * * \mathrm{p}<.001$. & & &
\end{tabular}

A significant interaction effect between helping realism and intrinsic religious motivation on helping was also observed, $\chi^{2}(3)=32.27, p<.001$, Nagelkerke's $R^{2}=.37$. Beta weights for the final regression model are shown in Table 3. The interaction indicates that, in the realistic helping condition, higher intrinsic motivation predicts increased helping rates; contrarily, in the hypothetical group, higher intrinsic motivation predicts a decrease in helping. 
Table 3

Predicting Yes/No Helping from Helping Realism, Intrinsic Religious Motivation, and Their Interaction

\begin{tabular}{lccccc}
\hline & $B$ & $S E$ & Wald & $d f$ & Odds Ratio \\
\hline Helping & $-2.33^{* * *}$ & .49 & 22.29 & 1 & .10 \\
Realism & & & & & \\
Intrinsic & .61 & .32 & 3.72 & 1 & 1.84 \\
& & & & & \\
Interaction & $-1.18^{*}$ & .47 & 6.13 & 1 & .31 \\
& & & & & \\
Constant & $1.52^{* * *}$ & .37 & 16.64 & 1 & 4.56 \\
\hline Note $* \mathrm{p}<.05 * * \mathrm{p}<.01 * * * \mathrm{p}<001$ & &
\end{tabular}

Note. $* \mathrm{p}<.05 . * * \mathrm{p}<.01 . * * * \mathrm{p}<.001$.

To better illustrate this interaction, low and high intrinsic religious motivation were distinguished using a median split, and a line graph was created depicting helping percentages for each group (see Figure 3). For ease of interpretation of the figure, in the realistic helping condition, $20.00 \%$ of low intrinsic motivation and $41.38 \%$ of high intrinsic motivation participants helped; in the hypothetical condition, $86.67 \%$ of low intrinsic motivation participants helped and $73.91 \%$ of high intrinsic motivation participants helped. Neither of the simple slopes tests for the realistic group $(\beta=.61$, Wald $\left.\chi^{2}(1)=3.72, n s\right)$ nor the hypothetical group $\left(\beta=-.57\right.$, Wald $\left.\chi^{2}(1)=2.56, n s\right)$ were significant. Although the two line slopes were significantly different from one another, neither of them was different from zero. 


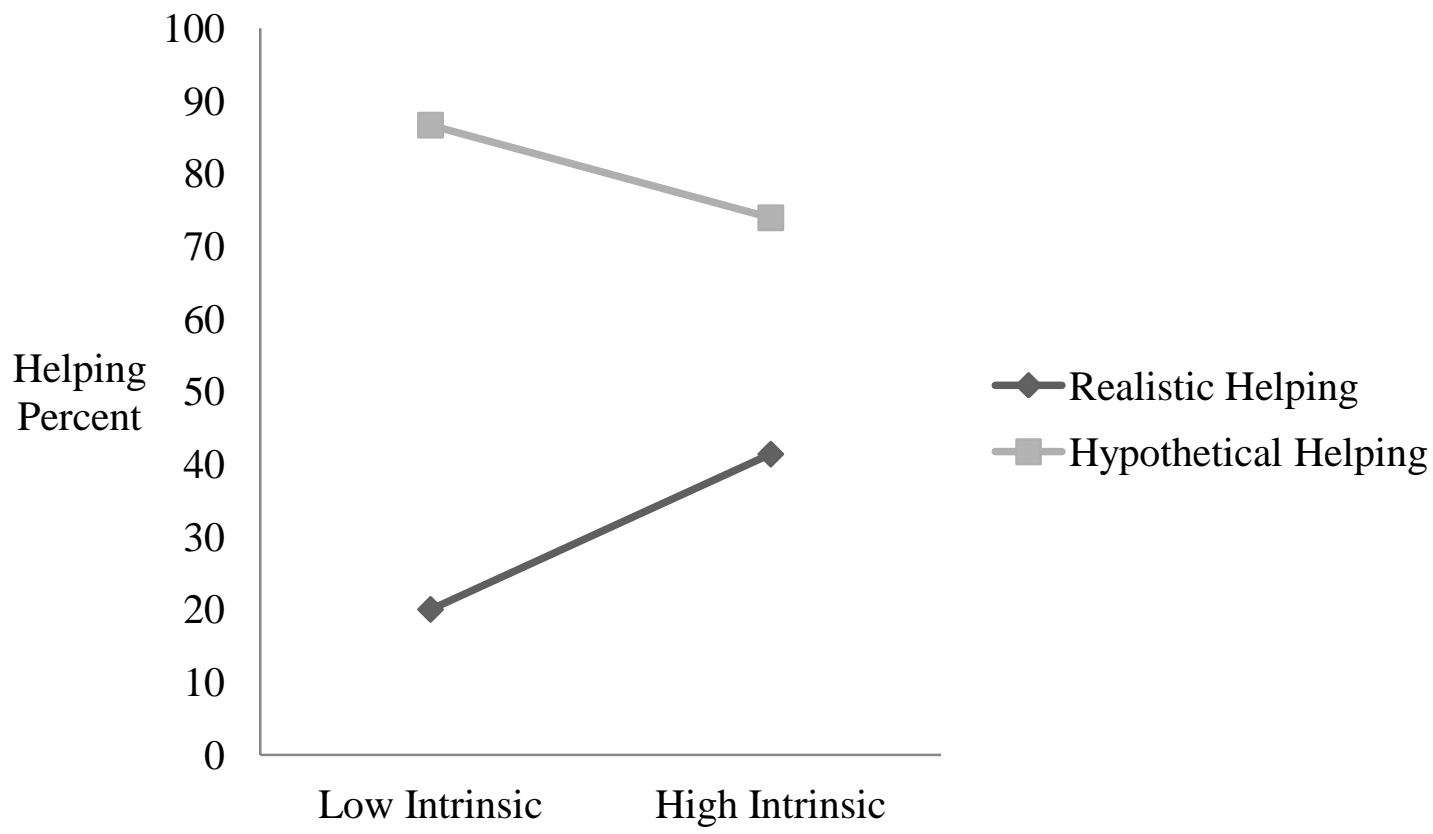

Figure 3. Line graph illustrating the interaction between helping realism and intrinsic religious motivation.

Analyses also showed a significant interaction effect between helping realism and PCBS external critique orientation on helping, $\chi^{2}(3)=31.24, p<.001$, Nagelkerke's $R^{2}=$ .36. Beta weights for the final model can be seen in Table 4. 
Table 4

Predicting Yes/No Helping from Helping Realism, PCBS External Critique, and Their Interaction

\begin{tabular}{lccccc}
\hline & $B$ & $S E$ & Wald & $d f$ & Odds Ratio \\
\hline $\begin{array}{l}\text { Helping } \\
\text { Realism }\end{array}$ & $-2.34 * * *$ & .49 & 22.41 & 1 & .10 \\
$\begin{array}{l}\text { External } \\
\text { Critique }\end{array}$ & -.65 & .35 & 3.33 & 1 & .52 \\
Interaction & $1.12 *$ & .53 & 4.50 & 1 & 3.08 \\
& & & & \\
Constant & $1.48 * * *$ & .37 & 16.12 & 1 & 4.40 \\
\hline Note. $* \mathrm{p}<.05 . * * \mathrm{p}<.01 . * * * \mathrm{p}<.001$. & &
\end{tabular}

Again, using a median split to separate low and high external critique, Figure 4 illustrates this interaction; higher external critique predicts a decrease in realistic helping, but an increase in hypothetical helping. In the realistic helping condition, $38.46 \%$ of low external critique and $25.00 \%$ of high external critique participants helped; in the hypothetical condition, $72.00 \%$ of low external critique participants helped and $88.89 \%$ of high external critique participants helped. Also for this interaction, neither of the simple slopes tests yielded significant results (realistic $\beta=-.65$, Wald $\chi^{2}(1)=3.33$, ns; hypothetical $\beta=.48$, Wald $\left.\chi^{2}(1)=1.47, n s\right)$. 


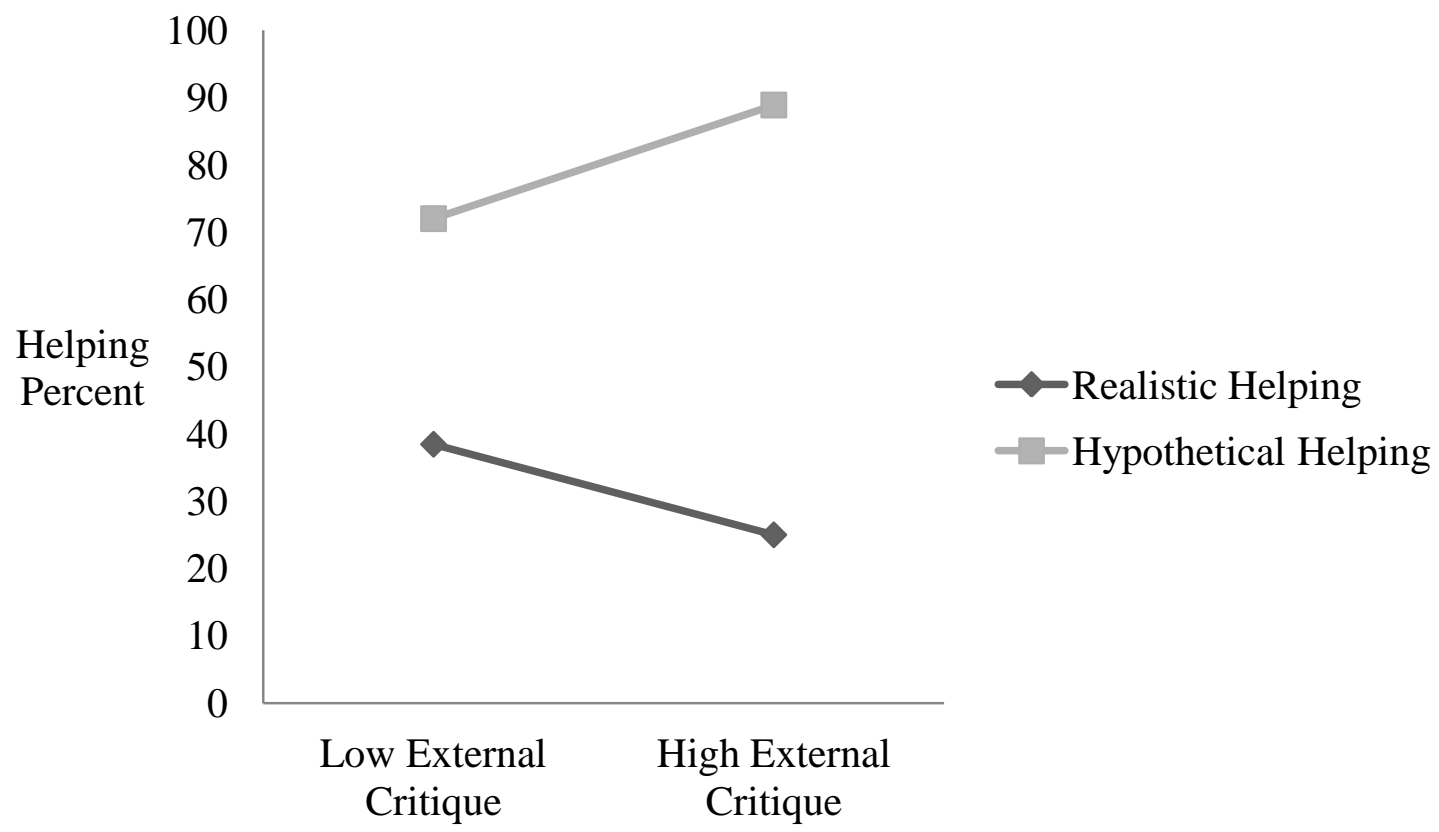

Figure 4. Line graph illustrating the interaction between helping realism and PCBS external critique religious orientation.

The third observed significant interaction effect on helping was between helping realism and IRI perspective taking, $\chi^{2}(3)=33.36, p<.001$, Nagelkerke's $R^{2}=.37$. Final model beta weights are listed in Table 5 . 
Table 5

Predicting Yes/No Helping from Helping Realism, IRI Perspective Taking, and Their Interaction

\begin{tabular}{lccccc}
\hline & $B$ & $S E$ & Wald & $d f$ & Odds Ratio \\
\hline $\begin{array}{l}\text { Helping } \\
\text { Realism }\end{array}$ & $-2.40 * * *$ & .51 & 22.07 & 1 & .09 \\
$\begin{array}{l}\text { Perspective } \\
\text { Taking }\end{array}$ & .66 & .34 & 3.70 & 1 & 1.93 \\
Interaction & $-1.32 *$ & .57 & 5.43 & 1 & .27 \\
& & & & \\
Constant & $1.61 * * *$ & .40 & 16.27 & 1 & 5.00 \\
\hline Note. $* \mathrm{p}<.05 . * * \mathrm{p}<.01 . * * * \mathrm{p}<.001$. & &
\end{tabular}

Like intrinsic religious motivation, the interaction suggests that increases in perspective taking predict increased real helping and decreased hypothetical helping (see Figure 5). In the realistic helping condition, $24.00 \%$ of low perspective taking and $40.00 \%$ of high perspective taking participants helped; in the hypothetical condition, $91.67 \%$ of low perspective taking participants helped and $72.41 \%$ of high perspective taking participants helped. As with the other simple slopes tests, neither the realistic group's slope $(\beta=.66$, Wald $\left.\chi^{2}(1)=3.70, n s\right)$ nor the hypothetical group's slope $\left(\beta=-.67\right.$, Wald $\left.\chi^{2}(1)=2.16, n s\right)$ was significant. 


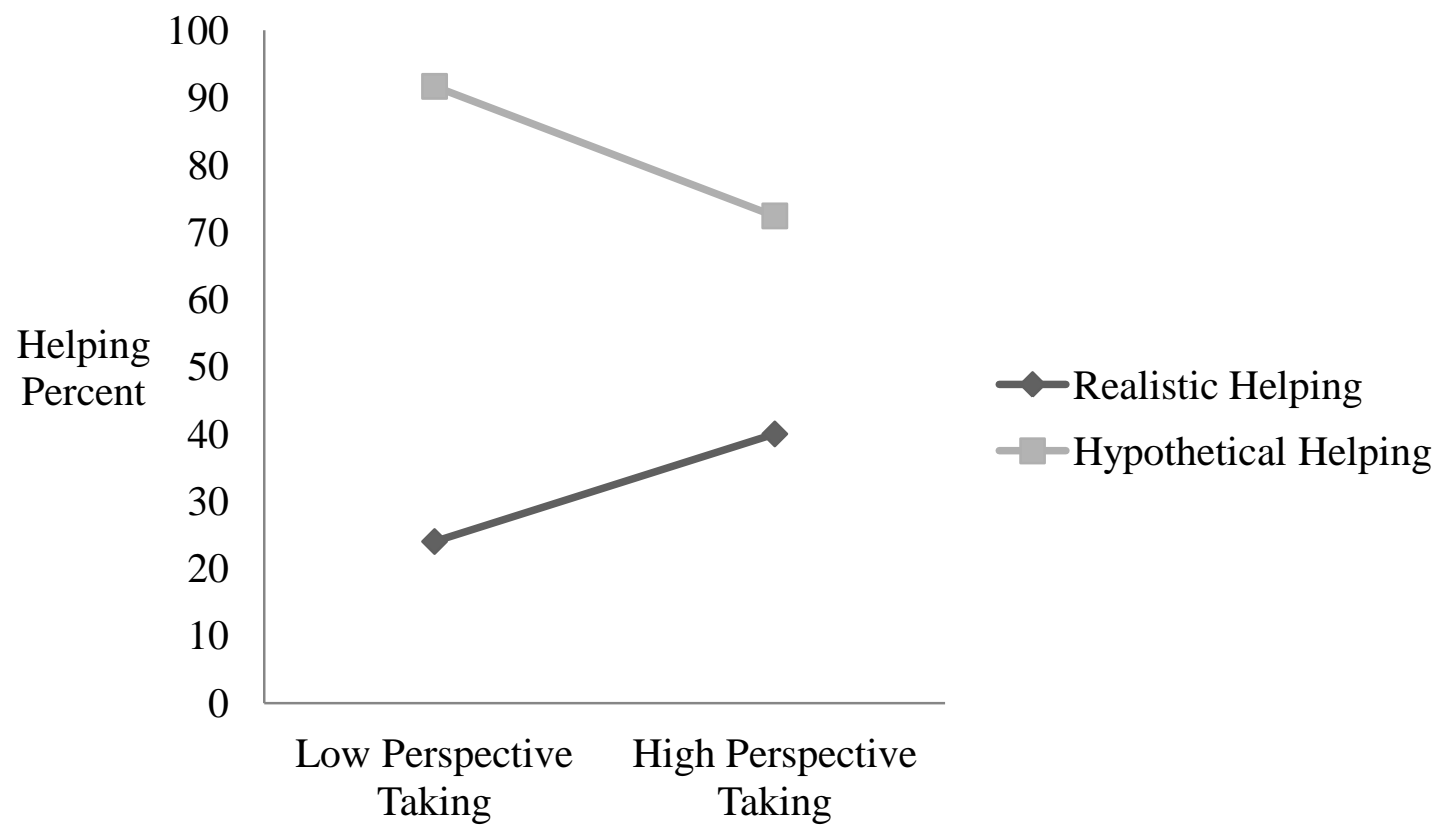

Figure 5. Line graph illustrating the interaction between helping realism and IRI perspective taking. 


\section{Discussion}

Intrinsic religious motivation, second naiveté religious orientation, and religious fundamentalism were all positively correlated with state empathic concern. This observation is congruent with previous studies' observations that individuals higher in intrinsic motivation (Maclean et al., 2004) and orientations that process religious information more symbolically (Duriez, 2004) tend to be higher in empathy. Oddly, this finding was not replicated with the various IRI subscales, measures of trait empathy frequently employed in the associative research. Although the relations between religiosity and state empathic concern mirrored those found in the hypothetical associative research, extrinsic-personal religious motivation, quest motivation, and the orthodoxy orientation were found to be more associated with various IRI subscales. These divergent findings regarding trait empathy were unexpected and the cause of the divergence is unknown; as will be discussed later, the current experimental design does not explicitly map onto the associative and non-associative research designs in a few regards, perhaps those discrepancies may be the source of the divergent results.

Regarding helping behaviors, there was a significant main effect of situation realism on helping rates, with participants indicating higher rates of hypothetical helping than realistic helping. Although no concrete hypotheses were formed regarding this main

effect, it was not at all unexpected. In the present case, what participants said they would hypothetically do to help Katie did not map onto what they actually did in a realistic 
situation. However, as Batson (2011) states, deciding whether or not to help somebody involves a cost/benefit analysis on the part of the actor. In the hypothetical condition, there is very little-to-no cost in saying that one would help Katie if given the chance. In contrast, participants in the realistic condition believed there would be real-world ramifications for their decision; saying "yes" to helping Katie would have been a much greater cost to them than for those in the hypothetical condition. Overall, participants in the hypothetical condition tended to grossly overestimate their helping behaviors compared to those in the realistic condition.

Unfortunately, the state empathic concern measure's reliability estimates were below acceptable levels and state empathic concern was found to be unrelated to helping in either condition. Because the empathy-altruism hypothesis requires that this relation be present (Batson, 2011), the current study could not draw any inferences about participants' altruistic motivations for helping. One reason this measure may not have been effective is because it is typically used when a perspective taking manipulation is employed (Batson, Batson, Griffitt, et al., 1989). That is, participants in one condition are asked to adopt the perspective of the person in the article (in this case, Katie Banks) and those in the other condition are asked to remain as objective as possible while reading the article, thus creating high- and low-empathic concern groups. In such an experimental paradigm, the state empathic concern measure may be sensitive enough to distinguish the high-empathic concern from the low-empathic concern participants. In the current study, however, the measure may not have been sensitive enough to detect differences among 
participants without the aid of an experimental manipulation. Nonetheless, despite not being able to draw conclusions regarding participants' motivations for helping, several associations between religiosity, trait empathy, and helping behaviors were identified.

The second naiveté subscale of the PCBS predicted increased dichotomous yes/no helping, regardless of group membership. This effect is somewhat supportive of the idea that symbolic (as opposed to literal) religious information processors are more helpful (Pichon \& Saroglou, 2009). Whereas prior research observed this relation in a hypothetical context, the current study extended the findings by observing them in a more realistic helping scenario. In addition to this observed main effect, three other predictors' interactions with helping realism also significantly predicted helping.

First, higher levels of intrinsic religious motivation predicted increased realistic helping and decreased hypothetical helping. This observation was unexpected since the hypothetical associative research observed a positive relation between intrinsic motivation and helping (Maclean et al., 2004) and the more realistic non-associative research found no such results (Batson et al., 1999). Regardless of previous findings, how does one explain the current observation? The interaction may potentially be attributed to participants' modesty. While the main effect of helping group membership indicates that people in general overestimate (or purposely inflate) their amount of helpfulness, perhaps those higher in intrinsic motivation do not wish to do so. Those high in intrinsic motivation did still overestimate their helpfulness, but they did so to a lesser extent than those lower in intrinsic motivation. Along with that decreased overestimation of 
helpfulness, those higher in intrinsic motivation tended to actually be more helpful in a realistic situation. This fits well with the definition of intrinsic religious motivation (Kahoe, 1985) in that if people view their religion (Christianity in the current study, for the most part) as a master motive in life, they would be more likely to espouse the beliefs of their faith: giving, helping, humility, and so forth.

The second significant interaction was that higher scores on the PCBS external critique subscale predicted decreases in real helping and increases in hypothetical helping. Again, this observation did not map on to previous associative research results (Pichon \& Saroglou, 2009). Although the current data cannot make inferences about these individuals' motivations, the pattern of saying that one would help if given the chance, but not actually helping could be attributed to a more egoistic motivation (Batson, 2011). Saying one would help if given the opportunity could cause one to experience positive feelings about oneself; but when the opportunity to truly help presents itself, the cost of actually helping is too high and most people opt to not help.

The third and final interaction followed a similar pattern as the first: higher IRI perspective taking predicted increased real helping and decreased hypothetical helping. Again, this finding may be attributed to some modesty component. Those who are better at adopting the perspective of those in need may be more apt to help when the need arises, but when asked about their potential helping behaviors, they do not wish to overestimate their helping ability. 


\section{Relation of Current Findings to Previous Research}

Many of the current study's hypotheses were not supported because the present results do not map on to those of the associative and non-associative religiosity research branches. Although the current hypotheses anticipated positive associations among religiosity, empathic concern, and helping in the hypothetical condition, the opposite was frequently observed. Neither intrinsic motivation nor second naiveté orientation were correlated with trait empathy, though they were related to increased state empathic concern, and the two interaction effects on helping involving intrinsic motivation and external critique orientation both indicated negative (albeit nonsignificant) associations between religiosity and hypothetical helping. However, the main effect of second naiveté on helping in both groups actually was representative of the associative branch's research findings (Pichon \& Saroglou, 2009).

Current results were largely unrepresentative of the non-associative research's

findings as well. In the realistic helping condition, no associations between religiosity and helping were anticipated, save for a potential relation between helping and quest motivation (Batson et al., 1999). However, the opposite was found, with intrinsic motivation being a better predictor of realistic helping than quest. For the most part, the current study's hypotheses went unsupported, suggesting that there is no overall association between religiosity and helping; it appears that certain motivations and orientations, depending on the nature of the situation, are better predictors of helping than others. 
Furthermore, while current patterns of results failed to map onto prior findings, several experimental factors contributed to divergences in the results. Obviously, situation realism strongly influenced helping responses; helping situation realism was a major point of difference between the associative and non-associative research, and it remained a critical factor for determining helping rates in the present study. Additionally, different patterns of results were observed for state empathic concern and trait empathy. Again, while the patterns did not match those found in previous research, there appears to be a qualitative difference between trait empathy and state empathic concern that yields divergent associations with religiosity.

\section{Limitations and Future Directions}

Several factors may have prevented the current findings from better replicating those of previous studies. The greatest limitation of the current study is power. Only 104 individuals participated in the study, 51 in the realistic helping condition, and 53 in the hypothetical condition. Consequently, the simple slope tests for the interactions were based on relatively small group sizes. There were several marginally significant regression results, many of which would have been statistically significant had sample size been larger.

The Katie Banks need situation also included a significant existential element: her current situation was prompted by the death of her parents. As religious beliefs also tend to contain a significant existential component, it may be that Katie's need situation 
triggered thoughts of death and dying, priming participants' religious attitudes toward death and making religious identities more salient at the time of the study. Though a MANOVA showed that religiosity variables themselves were unaffected across helping realism conditions, the nature of Katie's situation may have prompted shifts in religiosity that would not have differed across conditions. Replicating a similar procedure with a different need situation that does not involve death (e.g., a fictitious student needs help earning money to finance attending school) would remedy this potential factor.

The relationship between the target of the article and her need situation did not exactly map on to the situations in the associative research branch. In previous studies, both the target and their needs tended to be hypothetical in nature (Pichon \& Saroglou, 2009); in the current study, regardless of helping condition, Katie Banks is presented as a real target, not a hypothetical one. In the realistic helping condition, this is not a problem; to measure realistic helping, both the target and the need have to be real. In the hypothetical condition, previous research has employed hypothetical targets with hypothetical needs, whereas the present study featured an ostensibly real target with a hypothetical need. This disconnect between target and need realism may partially contribute to the current findings. Future research could manipulate target realism in order to isolate this potentially influential variable.

Finally, the current results were obtained using a convenience sample comprised primarily of white Christian college students in central Wisconsin. Thus, the findings may not generalize to other age groups, ethnicities, or religious traditions due to 
variations in life situations and experiences, religious backgrounds, and so forth. Future studies could employ different and more diverse samples to help better generalize the existence of the observed patterns across populations.

\section{Conclusions and Implications}

Although the current findings failed to replicate those of prior research, they nevertheless suggest that certain religious motivations and orientations are more associated with increased helping rates. Furthermore, although the presence of altruistic motivations among participants could not be discerned from the present data, the relations among religiosity, state empathic concern, trait empathy, and helping still yield valuable information about how religiosity relates to individuals' behaviors and attitudes. The experimental manipulation established realistic and hypothetical helping conditions, but the results from the realistic condition contain greater construct validity. That is, those higher in intrinsic religious motivation, second naiveté orientation, and perspective taking appear to be more helpful in the real world than individuals lower in those traits. Although the present results are by no means conclusive, future research would aid in reinforcing and further clarifying these observations. 
APPENDIX A

Student Newspaper Pilot Articles Study: Informed Consent 


\title{
Student Newspaper Pilot Articles Study: Informed Consent University of Wisconsin Oshkosh
}

The Department of Psychology supports the practice of protecting human participants in research. The following information is provided so that you can decide whether you wish to participate in the present study. Your participation is solicited but is strictly voluntary. We assure you that your name and responses will remain confidential.

If you decide to participate in this study, you will be asked to read a pilot news article. You will then be asked to complete questionnaires that assess your thoughts about and reactions to the article you read.

It is possible that you may experience strong emotional reactions to the news article you will read. If you agree to participate, you will be free to withdraw at any time and will still receive credit for the amount of time spent in the study. If you decide not to participate in this study, please let the researcher know and he or she will excuse you from the study. You do not need to tell the researcher your reasons for choosing not to participate. If you do decide to withdraw from the study, any information collected from you up to that point will then be destroyed.

All results will be recorded confidentially. We will not release information about you in any way or form that could identify you.

If you have any questions, please ask us or contact:

\author{
David A. Lishner, Ph.D. \\ Department of Psychology \\ University of Wisconsin Oshkosh \\ Oshkosh, WI 54901 \\ lishnerd@uwosh.edu \\ 920-915-2014
}

If you have any complaints about your treatment as a participant in this study, please call or write:

\section{Chair, Institutional Review Board for \\ Protection of Human Participants \\ c/o Grants Office \\ UW Oshkosh \\ 920-424-1415}

Although the chairperson may ask for your name, all complaints are kept in confidence.

Consent Statement: By signing the statement below, I am confirming that I am at least 18 years old and have received an explanation of the study. I agree to participate. I understand that my participation in this study is strictly voluntary, and that I may withdraw at any time. 
APPENDIX B

Student Newspaper Pilot Articles Study: Introduction 


\section{Student Newspaper Pilot Articles Study: Introduction}

This study is being conducted by Dr. Lishner in the Department of Psychology, as a service for the student newspaper. The newspaper staff is thinking about adding two new columns to the paper: "News from the Personal Side" and "Student Accomplishments." For the past few years, Dr. Lishner, whose research interests deal with audience response to mass media, has pilot-tested various news columns for the student newspaper.

As a participant in this study, you will be asked to randomly select one of eight brief pilot news articles, either from "News from the Personal Side" or "Student Accomplishments." Your reactions to the article will be assessed using questionnaires. Although the news articles used in this study are pilot articles, their content is factual. These articles have not and will not be printed in the newspaper; they will only be read by participants in this research.

At this time, please open the door to let the research assistant know you are ready to continue. 
APPENDIX C

Student Newspaper Pilot Article Instructions 


\section{Student Newspaper Pilot Article Instructions}

On the next page is the pilot article you selected. Please open the folder, read the article and fill out the reactions questionnaire provided to you. 
APPENDIX D

News from the Personal Side: Article 


\section{News from the Personal Side: UWO Student Struggles after Loss of Parents}

"This has been a total nightmare. I still feel like I'm living a horrible dream," Katie Banks said.

Last week, Banks's parents, Henry and Sue Banks, and her 12-year old sister, Jennifer, were killed in a head-on collision ten miles west of Madison.

The Banks family has resided in Oshkosh for only 4 months. At the time of the accident, they were returning to their former hometown to attend a birthday party for a friend of the family.

Banks, a student at the University of Wisconsin Oshkosh, is now faced with completing her college degree and taking care of her three surviving siblings - Annie, age 10; Matthew, age 7; and Zoe, age 4.

Banks has been granted temporary guardianship of her siblings. "I'll be honest. I'm really worried about graduating on time while providing for my brother and sisters," Banks said.

She is currently struggling with earning enough money to balance the costs of caring for her siblings and paying for school-related expenses. Banks is currently seeking donations from local, statewide, and national sources to help her and her siblings get through this difficult time.

Despite her fears, Banks tries to remain positive, "I realize life will have to go on some way or another. I just keep reminding myself that with luck things will turn out as best they can." 
APPENDIX E

News from the Personal Side: Reactions Questionnaire 


\section{News from the Personal Side: Reactions Questionnaire}

Directions: Please circle the number that best describes the degree to which you experienced each of these emotional reactions while reading the news article. Do not worry if you didn't experience several of these emotions; only a few may be relevant to the particular article you read. However, please be sure to circle a response for each emotion.

\begin{tabular}{|c|c|c|c|c|c|c|c|}
\hline \multicolumn{5}{|c|}{ not at all } & \multicolumn{3}{|c|}{ extremely } \\
\hline 1. happy & 1 & 2 & 3 & 4 & 5 & 6 & 7 \\
\hline 2. sad & 1 & 2 & 3 & 4 & 5 & 6 & 7 \\
\hline 3. compassionate & 1 & 2 & 3 & 4 & 5 & 6 & 7 \\
\hline 4. alarmed & 1 & 2 & 3 & 4 & 5 & 6 & 7 \\
\hline 5. troubled & 1 & 2 & 3 & 4 & 5 & 6 & 7 \\
\hline 6. softhearted & 1 & 2 & 3 & 4 & 5 & 6 & 7 \\
\hline 7. distressed & 1 & 2 & 3 & 4 & 5 & 6 & 7 \\
\hline 8. joyful & 1 & 2 & 3 & 4 & 5 & 6 & 7 \\
\hline 9. low-spirited & 1 & 2 & 3 & 4 & 5 & 6 & 7 \\
\hline 10. warm & 1 & 2 & 3 & 4 & 5 & 6 & 7 \\
\hline 11. worried & 1 & 2 & 3 & 4 & 5 & 6 & 7 \\
\hline 12. moved & 1 & 2 & 3 & 4 & 5 & 6 & 7 \\
\hline 13. upset & 1 & 2 & 3 & 4 & 5 & 6 & 7 \\
\hline 14. tender & 1 & 2 & 3 & 4 & 5 & 6 & 7 \\
\hline 15. sympathetic & 1 & 2 & 3 & 4 & 5 & 6 & 7 \\
\hline 16. disturbed & 1 & 2 & 3 & 4 & 5 & 6 & 7 \\
\hline 17. heavy-hearted & 1 & 2 & 3 & 4 & 5 & 6 & 7 \\
\hline 18. elated & 1 & 2 & 3 & 4 & 5 & 6 & 7 \\
\hline 19. disconcerted & 1 & 2 & 3 & 4 & 5 & 6 & 7 \\
\hline 20. sorrowful & 1 & 2 & 3 & 4 & 5 & 6 & 7 \\
\hline
\end{tabular}




\section{APPENDIX F}

Letter from Dr. Lishner 
Dear participant reading the Katie Banks article,

The student newspaper and I would like to thank you for participating in our study. Your cooperation and assistance are appreciated.

Because Katie's story will not be printed in the paper, it occurred to me that her need is still genuine and some participants might be willing to assist her. I've contacted Katie and although she was initially reluctant, she decided that she would be grateful to receive some assistance from anyone who is interested in giving it.

Basically, Katie needs some of your time. The student newspaper has provided her a list of organizations in the Oshkosh and Fox Cities regions, as well as state and national organizations, which might be willing to offer her financial assistance to help her and her family during this difficult time. She is currently working on a letter that she plans to send to these potential donors, but because her situation is urgent and her own time is limited, she needs help preparing the letters, stuffing and addressing envelopes, and keeping the necessary records of who has been contacted. If you wish to help Katie in this endeavor, the newspaper is willing to provide you with all the necessary materials, including postage. You can prepare the letters at home and at your own convenience.

Please consider whether you would like to assist Katie. Please keep in mind that your participation in this study in no way obligates you to help Katie. However, regardless of what you decide, you have been provided a form on which to indicate your decision. If you decide to help, please write your name and phone number in the space provided so that you can be contacted. Finally, please put the form in the envelope and then give the envelope to the research assistant so he or she can pass it on to me. If you decide to assist Katie, then I will pass along that information to a newspaper staff member.

Sincerely,

David Lishner, Ph.D 
APPENDIX G

Assistance Form 


\section{ASSISTANCE FORM}

Do you wish to assist Katie? Please indicate your response below:

No__ Yes

If no, leave the rest blank.

If yes, the student newspaper will contact you to discuss the best way to provide you with the necessary materials. Please indicate below the total number of hours you would be available over the next few weeks along with your name and phone number.

Number of hours available

NAME

PHONE

Thank you for considering this opportunity to help Katie. Please enclose this form in the provided envelope, seal it, and return it to the research assistant. 
APPENDIX H

News from the Personal Side: Helping Opinions Questionnaire 


\title{
News from the Personal Side: Helping Opinions Questionnaire
}

\author{
Article: Katie Banks
}

Directions: Because the proposed News from the Personal Side column would publish stories dealing with important events in the lives of individuals within the community, we are interested in finding out how reading such stories might affect people's desire to volunteer their assistance to those involved in the events described. Listed below are some questions that ask about your willingness to assist/interact with the individual(s) described in the specific article you selected.

\section{Suppose after reading the article you selected you were given an opportunity to assist Katie Banks:}

1. Would you be willing to assist Katie by helping her seek financial assistance from local and national organizations by helping her prepare letters, stuff and address envelopes, etc.?

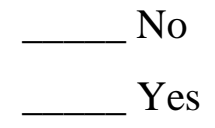

If yes, indicate how many hours you would be willing to do this over the next few weeks:

2. Would you be willing to provide childcare (i.e. baby sit) for Katie and her siblings?

No

Yes

If yes, indicate how many hours you would be willing to do this over the next few weeks: 
3. Would you be willing to offer transportation to Katie (e.g., drive her to the grocery store, drive her to school, drive her to pick up her siblings from school, etc.)?

No
Yes

If yes, indicate how many hours you would be willing to do this over the next few weeks:

4. Would you be willing to offer Katie Banks monetary assistance?

No

Yes

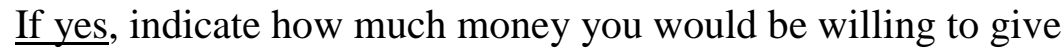
her: 
APPENDIX I

Evaluation Form 
Appendix I

\section{Evaluation Form: News from the Personal Side}

Directions: Please answer each of the following questions.

1. What was discussed in your article?

2. How interesting was the news article?

Not at all

$\begin{array}{llllllll}1 & 2 & 3 & 4 & 5 & 6 & 7\end{array}$

3. How likely would you be to read an article like this from the student newspaper?

Not at all

1

2

3

4

5

6

Very Likely

7

4. How worthwhile are articles of this nature?

Not at all

1
2

3
4
5
Extremely Worthwhile

6 7

5. How likeable did you find the person in the article?

Not at all
1

2

3

4

5

Extremely

Likable

6

7

6. To what extent do you value the person in the article?

Not at all
1
2
3
4
5
$\begin{array}{lll}6 & 7\end{array}$

Very Much

7. How much do you value the welfare of the person in the article?

Not at all

1

2

3

4

5

Very Much

$\begin{array}{ll}6 & 7\end{array}$ 
8. To what extent did the person in the article seem vulnerable?

Not at all

1
2 3 4 5

Extremely Vulnerable

9. How great was the current need of the person in the article?

Not at all
1
2
3
4
5
Very Great

10. To what extent did you imagine the thoughts and feelings of the person in the article?

Not at all

1 2

3

4

5

Very Much

7

11. To what extend did you imagine yourself in the situation of the person in the article?

Not at all
1
2
3
4
5
7

Very Much

12. To what extent were you objective and detached while reading the article?

Not at all

$$
1
$$
2

3

4

5

Very Much 7

13. How similar to yourself did you perceive the person in the article to be?

Not at all
1
2
3
4
5
6

Extremely

Similar

14. Below are seven pictures that depict possible ways of viewing the relationship between two people. Please circle one of these seven pictures that best indicates the extent to which you feel that you and the person in the article are connected.

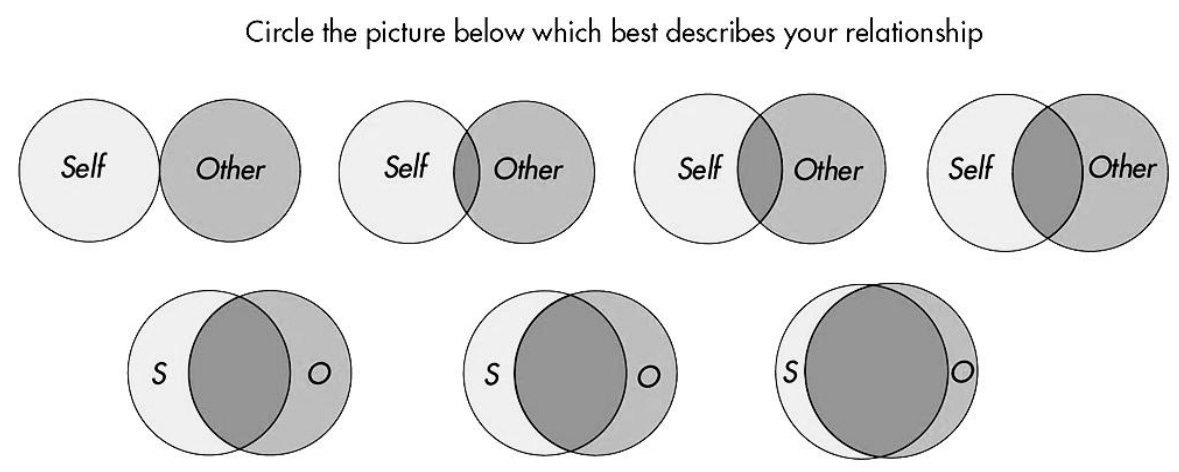


15. To what extent do you see yourself and the person in the article as part of the same group?

Not at all

1
2 3 4 5 Very Much 7

16. To what extent would you use to term "we" to describe your relationship with the person in the article?

Not at all

1

2

3

4

5

Very Much

$6 \quad 7$ 
APPENDIX J

Personal Perspective Questionnaires Introduction 
This packet contains several Personal Perspective Questionnaires that help us understand students and therefore, the types of articles they may find interesting. Please fill out each one and place it back into the envelope. Take as much time you need to answer each questionnaire with the response that best describes you. The researcher will not look at it, but forward it onto the person who does data collection.

Please open the door to let the researcher know you are finished. 
APPENDIX K

General Demographics Survey 
Directions: Please answer each question below to the best of your ability.

1. What is your sex? (Circle one)

Male

Female

2. What is your age (in years)?

3. What is your ethnicity (Check one)

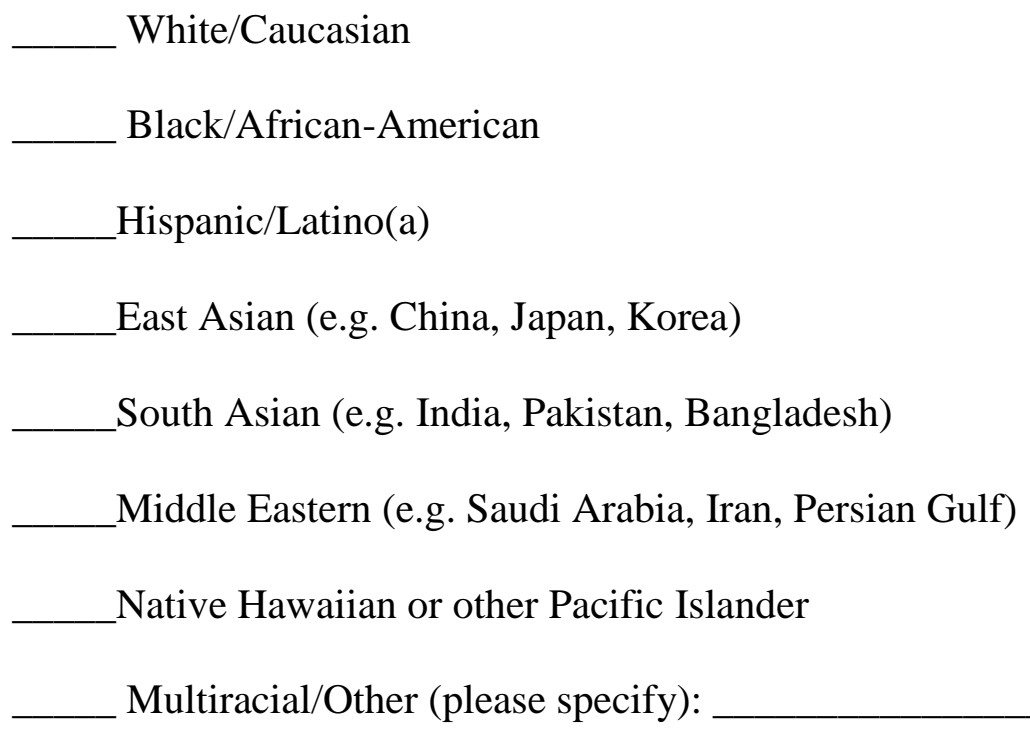

4. What is your current year in school? (Check one)

Freshman

Sophomore

Junior

Senior 
5. How would you describe your political orientation? (circle one)

$-3$

Liberal
$-2$

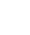

$-1$

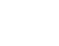

2

Moderate
3

Conservative

6. Which political party do you most strongly identify with? (Check one)

Republican

Democrat

Independent

Other, please specify (e.g. Green Party):

7. How strongly do you identify with that political party? (Circle one)

$\begin{array}{ccccccc}1 & 2 & 3 & 4 & 5 & 6 & 7 \\ \text { Very little } & & & \text { Somewhat } & & & \text { Very much }\end{array}$

8. Are you presently employed? (Circle one) Yes No

9. If so, how many hours per week do you work?

10. What is your average annual income?

11. Where is your present residence? (Check one)

On campus

Off campus (with family)

Off campus (not with family) 
APPENDIX L

Religious Demographics Survey 
Directions: Please answer each question below to the best of your ability.

1. Which of the following best describes your religious orientation? (Check one) Atheist (I do not believe in a higher power) Agnostic (I am unsure whether a higher power exists) Religious/Spiritual (I do believe in a higher power)

2. Which of the following religious groups do you identify with? I don't identify with a group Christian, please specify denomination (e.g. Catholic): Other, please specify (e.g. Judaism, Islam):

3. In general, how religious do you consider yourself to be? (Circle one)

$\begin{array}{ccccccc}1 & 2 & 3 & 4 & 5 & 6 & 7 \\ \text { Not at all } & & & & & & \text { Extremely } \\ \text { Religious } & & & & & & \text { Religious }\end{array}$

4. How spiritual do you consider yourself to be?

$\begin{array}{ccccccc}1 & 2 & 3 & 4 & 5 & 6 & 7 \\ \text { Not at all } & & & & & & \begin{array}{r}\text { Extremely } \\ \text { Spiritual }\end{array}\end{array}$


5. How often do you attend religious services? (Check one)

Never
Less than once per year
Once per year
Once or twice per year

Once per month
2-3 times per month
Nearly every week
Every week
Several times per week

6. Besides religious services, how often do you participate in other activities at a place of worship?

Never
L__ Less than once per year
Once per year
Once or twice per year
Several times per year

Once per month
2-3 times per month
Nearly every week
Every week
Several times per week


APPENDIX M

Intrinsic/Extrinsic - Revised Scale 
Directions: Please respond to each statement by indicating how much you agree or disagree with it. Write the number in the space provided, using the following rating scale:

$\begin{array}{ccccc}1 & 2 & 3 & 4 & 5 \\ \text { Strongly } & & & & \text { Strongly } \\ \text { Disagree } & & & & \text { Agree }\end{array}$

1. I enjoy reading about my religion.

2. I go to church because it helps me to make friends.

3. It doesn't much matter what I believe so long as I am good.

4. It is important to me to spend time in private thought and prayer.

5. I have often had a strong sense of God's presence.

6. I pray mainly to gain relief and protection.

7. I try hard to live all my life according to my religious beliefs.

8. What religion offers me most is comfort in times of trouble and sorrow.

9. Prayer is for peace and happiness.

10. Although I am religious, I don't let it affect my daily life.

11. I go to church mostly to spend time with my friends.

12. My whole approach to life is based on my religion.

13. I go to church mainly because I enjoy seeing people I know there.

14. Although I believe in my religion, many other things are more important in life. 
APPENDIX N

Quest Scale 
Directions: Please respond to each statement by indicating how much you agree or disagree with it. Write the number in the space provided, using the following rating scale:

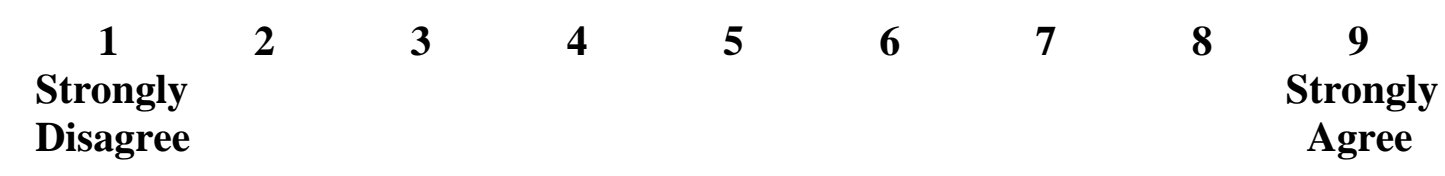

1. As I grow and change, I expect my religion to also grow and change.

2. I am constantly questioning my religious beliefs.

3. It might be said that I value my religious doubts and uncertainties.

4. I was not very interested in religion until I began to ask questions about the meaning and purpose of my life.

5. For me, doubting is an important part of what it means to be religious.

6. I do not expect my religious convictions to change in the next few years.

7. I find religious doubts upsetting.

8. I have been driven to ask religious questions out of a growing awareness of the tensions of my world and in my relation to my world.

9. My life experiences have led me to rethink my religious convictions.

10. There are many religious issues on which my views are still changing.

11. God wasn't very important to me until I began to ask questions about the meaning of my own life.

12. Questions are far more central to my religious experience than are answers. 
APPENDIX O

Post-Critical Belief Scale 
Directions: Please respond to each statement by indicating how much you oppose or agree with it. Write the number in the space provided, using the following rating scale:

$\begin{array}{ccccccc}1 & 2 & 3 & 4 & 5 & 6 & \begin{array}{c}7 \\ \text { Completely } \\ \text { Opposed }\end{array}\end{array}$

1. The Bible holds a deeper truth which can only be revealed by personal reflection.

2. God has been defined for once and for all and therefore is immutable.

3. Faith turns out to be an illusion when one is confronted with the harshness of life.

4. The Bible is a rough guide in the search for God, and not a historical account.

5. Even though this goes against modern rationality, Mary truly remained a virgin.

6. Each statement about God is a result of the time in which it was made.

7. Even though the Bible was written a long time ago, it retains a basic message.

8. Only the major religious traditions guarantee admittance to God.

9. The manner in which humans experience God will always be colored by society.

10. Ultimately, there is only one correct answer to each religious question.

11. The world of Bible stories is so far removed from us, that it has little relevance.

12. Science has made a religious understanding of life superfluous.

13. God grows together with the history of humanity and therefore is changeable. 


$\begin{array}{ccccccc}1 & 2 & 3 & 4 & 5 & 6 & \begin{array}{c}7 \\ \text { Completely } \\ \text { Opposed }\end{array}\end{array}$

14. My ideology is only one possibility among so many others.

15. I think that Bible stories should be taken literally, as they are written.

16. Despite the injustices caused by Christianity, Christ's message remains valuable.

17. In the end, faith is nothing more than a safety net for human fears.

18. Faith is an expression of a weak personality. 


\section{APPENDIX P}

Revised Religious Fundamentalism Scale 
Directions: Please respond to each statement by indicating how much you agree or disagree with it. Write the number in the space provided, using the following rating scale:

$\begin{array}{ccccccccc}-4 & -3 & -2 & -1 & 0 & 1 & 2 & 3 & 4 \\ \begin{array}{c}\text { Strongly } \\ \text { Disagree }\end{array} & & & & \text { Neutral } & & & & \begin{array}{c}\text { Strongly } \\ \text { Agree }\end{array}\end{array}$

1. God has given humanity a complete, unfailing guide to happiness and salvation, which must be totally followed.

2. No single book of religious teachings contains all the intrinsic, fundamental truths about life.

3. The basic cause of evil in this world is Satan, who is still constantly and ferociously fighting against God.

4. It is more important to be a good person than to believe in God and the right religion.

5. There is a particular set of religious teachings in this world that are so true, you can't go any "deeper" because they are the basic, bedrock message that God has given humanity.

6. When you get right down to it, there are basically only two kinds of people in the world: the Righteous, who will be rewarded by God; and the rest, who will not.

7. Scriptures may contain general truths, but they should NOT be considered completely, literally true from beginning to end.

8. To lead the best, most meaningful life, one must belong to the one, fundamentally true religion.

9. "Satan" is just the name people give to their own bad impulses. There really is no such thing as a diabolical "Prince of Darkness" who tempts us.

10. Whenever science and sacred scripture conflict, science is probably right. 
$-4$

Strongly

Disagree
$-2 \quad-1$

$-1$
2 Neutral
3 Strongly Agree

11. The fundamentals of God's religion should never be tampered with, or compromised with others' beliefs.

12. All of the religions in the world have flaws and wrong teachings. There is no perfectly true, right religion. 


\section{APPENDIX Q}

Interpersonal Reactivity Index 
Directions: Below is a list of 28 self-descriptive statements. In the space next to each statement please indicate the degree to which the statement describes you by choosing a number from the following scale:

\section{$\begin{array}{llllllll}\text { (Does not describe me well) } & 0 & 1 & 2 & 3 & 4 & 5 & \text { (Describes me very well) }\end{array}$}

1. I daydream and fantasize, with some regularity, about things that might happen to me.

2. I often have tender, concerned feelings for people less fortunate than me.

3. I sometimes find it difficult to see things from the "other guy's" point of view.

4. Sometimes I don't feel very sorry for other people when they are having problems.

5. I really get involved with the feelings of the characters in a novel.

6. In emergency situations, I feel apprehensive and ill-at-ease.

7. I am usually objective when I watch a movie or play, and I don't often get completely caught up in it.

8. I try to look at everybody's side of a disagreement before I make a decision.

9. When I see someone being taken advantage of, I feel kind of protective towards them.

10. I sometimes feel helpless when I am in the middle of a very emotional situation.

11. I sometimes try to understand my friends better by imagining how things look from their perspective.

12. Becoming extremely involved in a good book or movie is somewhat rare for me.

13. When I see someone get hurt, I tend to remain calm.

14. Other people's misfortunes do not usually disturb me a great deal. 


\section{$\begin{array}{llllllll}\text { (Does not describe me well) } & 0 & 1 & 2 & 3 & 4 & 5 & \text { (Describes me very well) }\end{array}$}

15. If I'm sure I'm right about something, I don't waste much time listening to other people's arguments.

16. After seeing a play or movie, I have felt as though I were one of the characters.

17. Being in a tense emotional situation scares me.

18. When I see someone being treated unfairly, I sometimes don't feel very much pity for them.

19. I am usually pretty effective in dealing with emergencies.

20. I am often quite touched by things that I see happen.

21. I believe that there are two sides to every question and try to look at them both.

22. I would describe myself as a pretty soft-hearted person.

23. When I watch a good movie, I can very easily put myself in the place of a leading character.

24. I tend to lose control during emergencies.

25. When I'm upset at someone, I usually try to "put myself in his shoes" for awhile.

26. When I am reading an interesting story or novel, I imagine how I would feel if the events in the story were happening to me.

27. When I see someone who badly needs help in an emergency, I go to pieces.

28. Before criticizing somebody, I try to imagine how I would feel if I were in their place. 
APPENDIX R

Debriefing Script 


\section{Debriefing Script}

Researcher: Before we end the study, I would like to take a few minutes to get your reactions to the study in your own words. Would it be okay if I wrote down any comments you may have?

[Participants almost always answer "yes" to this question.]

Researcher: Great! So, what are your reactions to the study?

[Any comments made by participant are written down. This open-ended question is followed by more specific questions about different aspects of the study if the participant does not spontaneously discuss them. For example, the researcher should ask about the following:

What did you think about the news article?

Have you or anyone you know been in a similar situation? Or that has been in a car accident?

What did you think about the feelings questionnaire? What did you think about the evaluation form?

What did you think about Dr. Lishner's Letter (or Helping Opinions Questionnaire)? What did you think about the Personal Perspective Questionnaires?

Researcher: At any point during the study did you think there was something more to the study? Did you at any point think that maybe there was something more to the study than what I've told you so far? Now that I mention it, can you think of any aspect of the study that seems strange or unusual?

If they begin to figure out the study: "Great! That's right! As you are starting to figure out, there is more to the study then you were originally told. What I'd like to do now is have you read over some information that will explain in more depth what the study was about. I will leave you alone to read over this information. When you are finished reading it, just open the door a crack and I will answer any additional questions you might have about the study."

If yes, and participant brings up an irrelevant deception in study .... That actually wasn't going on, but you are on the right track. As you are starting to figure out there is more to the study then you were originally told. What I'd like to do now is have you read over some information that will explain in more depth what the study was about. I will leave you alone to read over this information. 
When you are finished reading it, just open the door a crack and I will answer any additional questions you might have about the study."

If no, then ... That's good! Actually, there is more to the study then you were originally told. What I'd like to do now is have you read over some information that will explain in more depth what the study was about. I will leave you alone to read over this information. When you are finished reading it, just open the door a crack and I will answer any additional questions you might have about the study."

After the participant has read the Debriefing Information page and has opened the cubicle door the researcher will return to answer any questions the participant may have.

Researcher: Okay, now that you have read everything about the purpose of this study do you have any additional questions or concerns? As you can see there were some misleading aspects of this study. Do you understand the reasons for including those aspects and are you okay with that?

Researcher: Do you have any other questions or comments at this time? Can you think of any ways that we can improve the study?

Researcher: The last thing we ask is that you not discuss this study with anyone, at least until the end of the semester, so that other people have the opportunity to experience the study in a realistic manner. Would that be okay with you?

Researcher: Well, thank you for participating in the study and thank you for telling me about your reactions. It is very helpful for us and we really appreciate it! 


\section{APPENDIX S}

Student Newspaper Pilot Articles Study: Debriefing Information 


\section{Student Newspaper Pilot Articles Study: Debriefing Information}

Thank you for participating in this study. The purpose of this form is to provide you more in-depth information about the study. The actual purpose of this study is not to study people's reactions to pilot news articles. Rather, the actual purpose of this study is to examine whether religious and nonreligious people differ in their willingness to help someone in need. One factor that might affect differences between religious or nonreligious people's responses is whether participants believe the helping opportunity is real or hypothetical.

To examine this issue, we randomly assigned half the participants to a condition in which they were explicitly told the helping opportunity was real. The other half of participants were randomly assigned to a condition in which they were only told that the opportunities were hypothetical. Given these opportunities were examined in regard to religiosity, we then had you complete various measures of religiosity after reading the article. All participants received the same article and all participants were asked about whether they would help the person in the article. By doing this, we are able to see how the different experimental conditions might influence differences in how religious and nonreligious people respond when encountering a person in need.

As you may have guessed by now, there were a number of misleading things that you were told about this study. First, the study is not being conducted in collaboration with the student newspaper. The student newspaper is in no way affiliated with this study. Second, there was only one article, not eight, and the person and event you read about were fictional. Consequently, the helping opportunities also were fictional. If you received an assistance form, regardless of how you responded on it, you will not be contacted to provide assistance in the future. The purpose for giving you this misleading information was not to trick you. Rather, it was given to you to allow us to keep constant the person in need and the need situation that was described so that we could precisely determine whether or not the two experimental conditions we created were solely responsible for religious and nonreligious people's reactions to encountering a person in need. If we told participants the full truth about the purpose of the study in the beginning and that the article is actually not real, then participants may experience the situation as fictional or as pretend. This could lead participants to react very differently from how they would react in real-life situations when encountering people in need. Also, in some circumstances, if participants know about the actual purpose of a study, then they may feel compelled to report their reactions in an untruthful manner. For these reasons, when psychologists examine certain psychological processes, they may withhold some information about a study or provide participants with some information about the study that is misleading. We realize that you may feel a bit uncomfortable about having been told misleading information, but we want to assure you that it only was done to ensure that your experience in this study was as realistic as possible. Furthermore, it is important to remember that there is no correct or incorrect behavior or response to any of the questionnaires or materials in this study. However, if you still have any concerns about this study, then please speak with the research assistant about your concerns or contact Dr. David Lishner (at lishnerd@uwosh.edu). Either of these individuals will be more than happy to talk with you about any concerns you may have.

Again, thank you very much for your participation. We value the time and energy you spent in this study and it is our hope that the data you have provided will help us to better understand human psychology. 


\section{References}

Allport, G. W. \& Ross, J. M. (1967). Personal religious orientation and prejudice. Journal of Personality and Social Psychology, 5(4), 433-443.

Altemeyer, B. \& Hunsberger, B. (2004). A revised religious fundamentalism scale: The short and sweet of it. The International Journal for the Psychology of Religion, 14(1), 47-54.

Batson, C. D. (2011). Altruism in humans. New York: Oxford University Press, Inc.

Batson, C. D., Batson, J. G., Griffitt, C. A., Barrientos, S. Brandt, J. R., Sprengelmeyer, P., \& Bayly, M. J. (1989). Negative-state relief and the empathy-altruism hypothesis. Journal of Personality and Social Psychology, 56(6), 922-933.

Batson, C. D., Denton, D. M., \& Vollmecke, J. T. (2008). Quest religion, antifundamentalism, and limited versus universal compassion. Journal for the Scientific Study of Religion, 47(1), 135-145.

Batson, C. D., Eidelman, S. H., Higley, S. L., \& Russell, S. A. (2001). “And who is my neighbor?” II: Quest religion as a source of universal compassion. Journal for the Scientific Study of Religion 40(1), 39-50.

Batson, C. D., Floyd, R. B., Meyer, J. M., \& Winner, A. L. (1999). “And who is my neighbor?:" intrinsic religion as a source of universal compassion. Journal for the Scientific Study of Religion 38(4). 445-457. 
Batson, C. D., Oleson, K. C., Weeks, J. L., Heal, S. P., Reeves, P. J., Jennings, P., \& Brown, T. (1989). Religious prosocial motivation: Is it altruistic or egoistic? Journal of Personality and Social Psychology, 57(5), 873-884.

Batson, C. D. \& Schoenrade, P. A. (1991a). Measuring religion as quest: 1) Validity concerns. Journal for the Scientific Study of Religion, 30(4), 416-429.

Batson, C. D. \& Schoenrade, P. A. (1991b). Measuring religion as quest: 2) Reliability concerns. Journal for the Scientific Study of Religion, 30(4), 430-447.

Bingaman, K. A. (2003). Freud and Faith: Living in the Tension. Albany, NY: State University of New York Press.

Davis, M. H. (1983). Measuring individual differences in empathy: Evidence for a multidimensional approach. Journal of Personality and Social Psychology, 44(1), 113-126.

De Corte, K., Buysse, A., Verhofstadt, L. L., Roeyers, H., Ponnet, K., \& Davis, M. H. (2007). Measuring empathic tendencies: Reliability and validity of the Dutch version of the Interpersonal Reactivity Index. Psychologica Belgica, 47(4), 235260.

Duriez, B. (2004). Are religious people nicer people? Taking a closer look at the religionempathy relationship. Mental Health, Religion, \& Culture, 3, 249-254. doi: $10.1080 / 13674670310001606450$ 
Duriez, B., Fontaine, J. R. J., \& Hutsebaut, D. (2000). A further elaboration of the PostCritical Belief Scale: Evidence for the existence of four different approaches to religion in Flanders-Belgium. Psychologica Belgica, 40(3), 153-181.

Duriez, B., Soenens, B., \& Hutsebaut, D. (2004). Introducing the shortened Post-Critical Belief Scale. Personality and Individual Differences, 38, 851-857.

Fontaine, J. R. J., Duriez, B., Luyten, P., \& Hutsebaut, D. (2003). The internal structure of the Post-Critical Belief Scale. Personality and Individual Differences, 35, 501518.

Gorsuch, R. L. \& McPherson, S. E. (1989). Intrinsic/Extrinsic Measurement: I/E-Revised and single-item scales. Journal for the Scientific Study of Religion, 28(3), 348354.

Hill, P. C. \& Hood, R. W. (Eds.). (1999). Measures of religiosity. Birmingham, AL: Religious Education Press.

Hunsberger, B., Alisat, S., Pancer, S. M. \& Pratt, M. (1996). Religious fundamentalism and religious doubts: Content, connections, and complexity of thinking. International Journal for the Psychology of Religion, 6(3), 201-220.

Kahoe, R. D. (1985). The development of intrinsic and extrinsic religious orientations. Journal for the Scientific Study of Religion, 24(4), 408-412.

Kirkpatrick, L. A. \& Hood, R. W. (1990). Intrinsic-extrinsic religious orientation: The boon or bane of contemporary psychology of religion? Journal for the Scientific Study of Religion, 29(4), 442-462. 
Maclean, A. M., Walker, L. J., \& Matsuba, M. K. (2004). Transcendence and the moral self: Identity integration, religion, and moral life. Journal for the Scientific Study of Religion 43(3), 429-437. doi: 10.1111/j.1468-5906.2004.00245.x

Pargament, K. I. (1992). Of means and ends: Religion and the search for significance. International Journal for the Psychology of Religion, 2(4), 201-229.

Pichon, I. \& Saroglou, V. (2009). Religion and helping: Impact of target thinking styles and just-world beliefs. Archive for the Psychology of Religion, 31, 215-236. doi: $10.1163 / 157361209 X 424466$

Saroglou, V., Pichon, I., Trompette, L., Verschueren, M., \& Dernelle, R. (2005). Prosocial behavior and religion: New evidence based on projective measures and peer ratings. Journal for the Scientific Study of Religion 44(3), 323-348. doi: 10.1111/j.1468-5906.2005.00289.x

Seth, I. R. \& Gupta, P. (1984). Religion, alter, situation, and altruism. Journal of Psychological Researches 28(2), 107-113.

Wulff, D. M. (1991). Psychology of Religion. New York, NY: John Wiley \& Sons. Wuthnow, R. \& Lewis, V. (2008). Religion and altruistic U.S. foreign policy goals: Evidence from a national survey of church members. Journal for the Scientific Study of Religion, 47(2), 191-209. doi: 10.1111/j.1468-5906.2008.00402.x

Zinnbauer, B. J. \& Pargament, K. I. (2005). Religiousness and spirituality. In R. F. Paloutzian \& C. L. Park (Eds.) Handbook of the psychology of religion and spirituality (pp. 21-42). New York, NY: The Guilford Press. 